\title{
How to Keep the Brain Awake? The Complex Molecular Pharmacogenetics of Wake Promotion
}

\author{
Sibah Hasan', Sylvain Pradervand ${ }^{2}$, Abdellah Ahnaou ${ }^{3}$, Wilhelmus Drinkenburg ${ }^{3}$, Mehdi Tafti*,' and Paul \\ Franken*, I \\ 'Center for Integrative Genomics, University of Lausanne, Lausanne, Switzerland; '2Lausanne DNA Array Facility, University of Lausanne, \\ Lausanne, Switzerland; 3Johnson \& Johnson, Pharmaceutical Research \& Development, Beerse, Belgium
}

\begin{abstract}
Wake-promoting drugs are widely used to treat excessive daytime sleepiness. The neuronal pathways involved in wake promotion are multiple and often not well characterized. We tested d-amphetamine, modafinil, and YKPIOA, a novel wake-promoting compound, in three inbred strains of mice. The wake duration induced by YKPIOA and d-amphetamine depended similarly on genotype, whereas opposite strain differences were observed after modafinil. Electroencephalogram (EEG) analysis during drug-induced wakefulness revealed a transient $\sim 2 \mathrm{~Hz}$ slowing of theta oscillations and an increase in beta-2 $(20-35 \mathrm{~Hz})$ activity only after YKP IOA. Gamma activity $(35-60 \mathrm{~Hz})$ was induced by all drugs in a drug- and genotype-dependent manner. Brain transcriptome and clustering analyses indicated that the three drugs have both common and specific molecular signatures. The correlation between specific EEG and gene-expression signatures suggests that the neuronal pathways activated to stay awake vary among drugs and genetic background. Neuropsychopharmacology (2009) 34, I625-1640; doi: I0.1038/npp.2009.3; published online 4 February 2009
\end{abstract}

Keywords: sleep; stimulant; EEG; theta; gamma; gene expression

\section{INTRODUCTION}

Excessive daytime sleepiness can be a serious and debilitating condition accompanying a wide range of sleep disorders such as narcolepsy, idiopathic hypersomnia, hypersomnia associated with psychiatric or neurological disorders, and breathing-related sleep disorders. Currently, modafinil is the most widely used wake-promoting drug to alleviate excessive daytime sleepiness, especially in the treatment of narcolepsy. In a substantial number of narcolepsy patients, modafinil is, however, not or only partially effective (Bastuji and Jouvet, 1988; Dauvilliers et al, 2002). As alternative wake-promoting compounds are not yet available, in 'modafinil-resistant' patients, amphetamines and amphetamine-like stimulants are prescribed despite the many known undesired side effects (Nishino and Mignot, 2005). Since the discovery of amphetamine's stimulant action (Alles, 1933), alternatives are being developed acting on wake-promoting neurotransmission such as histamine and catecholamines (Barbier et al, 2004; Bonaventure et al, 2007; Boutrel and Koob, 2004; Parmentier et al, 2007).

\footnotetext{
*Correspondence: Professor M Tafti, Center for Integrative Genomics, University of Lausanne, Génopode Bldg, Lausanne 1015, Switzerland, Tel: +4121692 3971/72, Fax: + 41226923965 ,

E-mail: mehdi.tafti@unil.ch or paul.franken@unil.ch

Received 23 July 2008; revised 29 December 2008; accepted 31 December 2008
}

In contrast to the pharmacology of sleep induction by GABAergic or GABA-modulating compounds, the mode of action of non-amphetaminic wake-promoting drugs remains poorly understood and might be achieved through a variety of pathways and mechanisms. YKP10A (aka R228060; [(R) - $(\beta$-amino-benzenepropyl) carbamate monohydrochloride]) is the hydrochloric acid salt of an optically pure phenylalanine derivative (see detailed information at: http://www.wipo.int/pctdb/en/wo.jsp?wo = 2006133393\&IA $=$ WO2006133393\&DISPLA), which has been developed for its potential antidepressant activity observed in animal models of depression (Gordon et al, 1998). YKP10A presents weak interactions at the dopamine transporter but no relevant interactions with serotonin or norepinephrine reuptake in receptor-binding studies (Gordon et al, 1998). Its antidepressant effect in humans is still under debate (Amsterdam et al, 2002). Among the most significant effects in human studies was insomnia (Amsterdam et al, 2002) and based on preliminary data, YKP10A was also shown to have wake-promoting action in rats (A Ahnaou and W Drinkenburg; unpublished observations). YKP10A's mode of action is unclear but may affect dopamine neurotransmission as its clinical profile resembles that of the dopamine-reuptake inhibitors nomifensive and bupropion (Amsterdam et al, 2002) although YKP10A does not appear to greatly reduce dopamine reuptake (Gordon et al, 1998). Also, modafinil is believed to act through the dopaminergic system although its precise mode of action remains unclear (Ballon and Feifel, 2006; Minzenberg and 
Carter, 2008; Parmentier et al, 2007; Wisor and Eriksson, 2005). Amphetamine is known to increase catecholamine release and inhibit their reuptake (Nishino and Mignot, 2005).

Differences in genetic background are likely to underlie part of the variation in the response to modafinil mentioned above. Numerous drug studies both in mice and humans have demonstrated that genetic-background differences in drug efficacy and their side effects are more a rule than an exception. Genetic background is therefore a crucial variable when evaluating novel drugs. Examples of specific gene polymorphism or transgenic models associated with altered efficacy of stimulants are, for amphetamine, the dopamine transporter (Lott et al, 2005; Wisor et al, 2001), homerla (Tappe and Kuner, 2006), casein kinase I- $\varepsilon$ (Palmer et al, 2005), and brain-derived neurotrophic factor (BDNF) (Flanagin et al, 2006); for modafinil, catechol-O-methyltransferase (Dauvilliers et al, 2002) and the dopamine transporter (Wisor et al, 2001); and for caffeine, the adenosine A2a receptor (Alsene et al, 2003; Retey et al, 2007). The finding that casein kinase I- $\varepsilon$ is involved in the response to amphetamine in mice (Palmer et al, 2005) was recently confirmed in humans (Veenstra-VanderWeele et al, 2006), demonstrating that the mouse model can be of direct relevance for predicting genetic-background effects in humans. Similar pharmacogenetic approaches in mice have been used to predict the response to antidepressant drugs in humans (Crowley et al, 2006).

Here we evaluate the wake-promoting efficacy of three stimulants in three inbred strains of mice. We have shown earlier that the compensatory sleep response and the changes in brain gene expression after enforced wakefulness greatly differ among these three genetic backgrounds (Franken et al, 2001, 1999; Maret et al, 2007). To gain insight into how wake-promoting compounds keep the brain awake, we emphasize first the spectral composition of the electroencephalogram (EEG) during drug-induced wakefulness, and second their effects on brain gene expression. Our results indicate that each stimulant leaves a genotype-dependant signature on both EEG and gene expression. Moreover, wakefulness induced by each drug might be qualitatively different as some induce slow theta oscillations whereas the others a high-frequency EEG activity, reminiscent of EEG activity during demanding cognitive tasks.

\section{MATERIALS AND METHODS}

\section{Animals}

Adult male mice from three inbred strains, DBA/2J (D2), $\mathrm{C} 57 \mathrm{BL} / 6 \mathrm{~J}(\mathrm{~B} 6)$, and AKR/J (AK), were used in this study. All mice (age: 10-11 weeks at the time of surgery; weight: 21 $32 \mathrm{~g}$ ) were purchased from Jackson Laboratory (Maine). Mice were kept individually in polycarbonate cages $(31 \mathrm{~cm} \times 18 \mathrm{~cm} \times 18 \mathrm{~cm})$ with food and water available ad libitum, and maintained on a 12-h light-dark cycle (lights on at 0900 hours) at an ambient temperature of $24.5-25.5^{\circ} \mathrm{C}$. The protocols used were approved by the Veterinary Office of the Canton of Vaud, Switzerland.

\section{Surgery}

EEG and EMG electrodes were implanted under deep anesthesia with a mixture of ketamine and xylazine (intraperitoneal, 75 and $10 \mathrm{mg} / \mathrm{kg}$, respectively, at a volume of $8 \mathrm{ml} / \mathrm{kg}$ ). Two gold-plated miniature screws (diameter, $1.1 \mathrm{~mm}$ ) served as EEG electrodes and were screwed into the cranium over the right cerebral hemisphere, in a frontoparietal position (according to Franken et al, 1998). Four additional anchor screws were implanted; one over the right hemisphere and three over the left hemisphere. Two semirigid gold wires served as EMG electrodes and were inserted between two neck muscles. The EEG and EMG electrodes were soldered to a connector and the anchor screws were cemented to the skull. Four to 8 days of recovery from surgery was allowed before animals were connected to the recording leads. A minimum of six adaptation days were scheduled before data collection.

\section{Protocol}

All mice used for EEG/EMG analyses were recorded continuously for $72 \mathrm{~h}$ using EMBLA $^{\mathrm{TM}}$ hardware and Somnologica- $3^{\mathrm{TM}}$ software, both developed by Flaga (Island). The first day served as baseline and was initiated at light onset (0900 hours); the second day was considered as the control condition with a saline injection; and the third day, a drug was administered. Sample sizes were the following: YKP10A: $n=20,18$, and 19; $d$-amphetamine: $n=6,8$, and 8; and modafinil $n=7,8$, and 8 , for D2, B6, and AK mice, respectively.

\section{Determining Drug Efficacy}

YKP10A (Johnson and Johnson, Beerse, Belgium) and $d$-amphetamine were dissolved in saline solution $(\mathrm{NaCl}$ $0.9 \%)$. Modafinil was not dissolved but suspended in saline solution by vortexing and injecting immediately to each mouse. Drug solutions were freshly prepared the same day before light onset. Shortly after light onset (0901 to 0917 hours), all drug and saline (serving as controls) solutions were administered by intraperitoneal injection at a volume of $5 \mathrm{ml} / \mathrm{kg}$ body weight.

B6 mice were used to determine a YKP10A dose that would induce a period of wakefulness in the same range as our standard sleep-deprivation protocol; that is $6 \mathrm{~h}$ (from 9:00 to 15:00). Five doses were administered: $25(n=9), 50$ $(n=9), 100(n=10), 150(n=6)$, and $200 \mathrm{mg} / \mathrm{kg}(n=6)$. To determine equally effective doses for $d$-amphetamine and modafinil, B6 mice received five $(1(n=3), 2(n=3), 4$ $(n=4), 5(n=5)$, and $8 \mathrm{mg} / \mathrm{kg}(n=5))$ and three doses $(100$ $(n=5), 200(n=5)$, and $300 \mathrm{mg} / \mathrm{kg}(n=6))$, respectively. Each mouse received one drug only (preceded by one saline injection). Sleep onset was defined as the time elapsed between the time of injection and the first sleep episode lasting at least $1 \mathrm{~min}$ and not interrupted by more than two 4-s epochs scored as wakefulness. On the basis of the doseresponse curves thus obtained in B6 mice (Figure 1), we decided on a dose of $150 \mathrm{mg} / \mathrm{kg}$ for YKP10A, $6 \mathrm{mg} / \mathrm{kg}$ for $d$ amphetamine, and $150 \mathrm{mg} / \mathrm{kg}$ for modafinil, for all subsequent studies. 

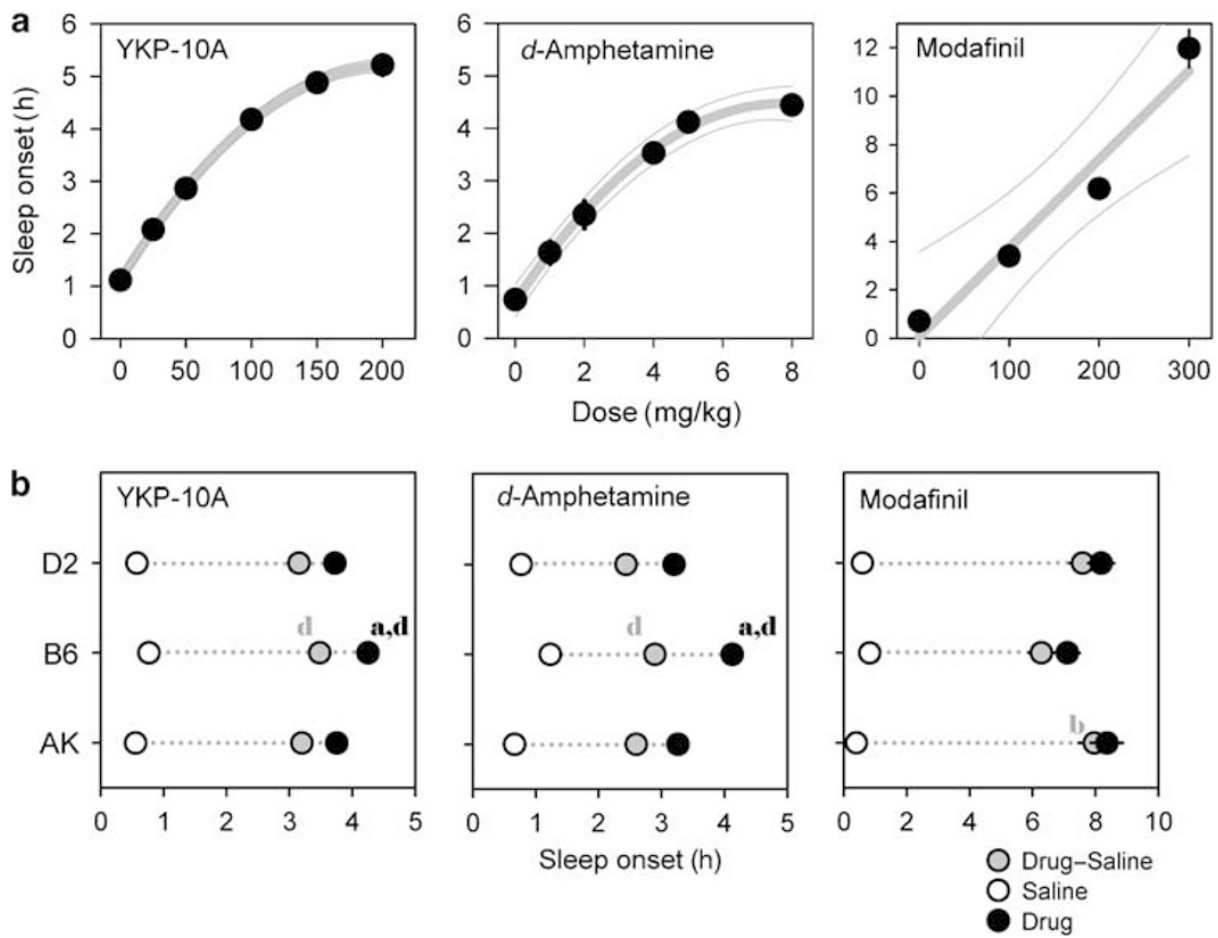

Figure I Effects of saline, YKPIOA, d-amphetamine, and modafinil on sleep onset. (a) Dose-response relationship for the delay in sleep onset in B6 mice for three wake-promoting drugs. Symbols represent mean ( \pm I SEM; $n=16-40,6-10,3-5$, and 5-6 for saline, YKPIOA, d-amphetamine, and modafinil, respectively; see Materials and Methods for details) values for sleep onset after light onset (thick gray lines represent first- and second-order fitted curves; thinner lines delimit the $95 \%$ confidence intervals). (b) Strain distribution pattern of the effects of a single injection of YKPIOA (I50 mg/kg), $\mathrm{d}$-amphetamine $(6 \mathrm{mg} / \mathrm{kg})$, and modafinil $(150 \mathrm{mg} / \mathrm{kg})$ in three inbred strains of mice (D2, B6, and AK). Symbols represent mean $( \pm$ I SEM; YKPIOA: $n=20$, 18, and 19; d-amphetamine: $n=6,8$, and 8; modafinil: $n=7,8$, and 8; for D2, B6, and AK, respectively) post-injection sleep-onset times. Open symbols denote saline control injection, closed black symbols drug injection, and gray symbols represent the mean difference between the effect of drug and saline injection within individual mice. Characters in superscript ( $a, b$, and d) indicate significant strain differences from AK (a), B6 (b), or D2 (d); P<0.05; t-tests. Note that SEMs are smaller than symbol size in most cases and that the time axis for modafinil is twice those of the other drugs.

\section{EEG Analyses}

Analog EEG and EMG signals were digitized at $2000 \mathrm{~Hz}$ and subsequently stored at $200 \mathrm{~Hz}$ on hard disc. The EEG was subjected to a discrete Fourier transformation, yielding power spectra (range: $0.25-90 \mathrm{~Hz}$; resolution: $0.25 \mathrm{~Hz}$; window function: hamming) for consecutive 4-s epochs.

The animal's behavior was classified as REM sleep, NREM sleep, or wakefulness, for consecutive 4-s epochs, on the basis of the EEG and EMG signals according to the standard criteria. REM sleep is characterized by regular theta oscillations $(5-9 \mathrm{~Hz})$ in the EEG and a low-amplitude EMG. During NREM sleep, the EEG amplitude is higher and dominated by both delta $(1-4 \mathrm{~Hz})$ and theta frequency components, whereas the EMG activity remains low. Wakefulness is characterized by a high and variable EMG activity and a low-amplitude mixed-frequency EEG signal. The behavioral states were determined by the visual inspection of the EEG and EMG signals, which were displayed on a PC screen. Four-second epochs containing EEG artifacts were marked so that they could be excluded from EEG spectral analyses.

Sleep onset was determined in all animals recorded. For quantitative EEG analyses, some animals had to be discarded due to artifacts in the EEG (YKP10A: $n=15,15$, 15 ; $d$-amphetamine: $n=6,6,8$; modafinil: $n=6,8,7$; for $\mathrm{D} 2$, $\mathrm{B} 6$, and $\mathrm{AK}$, respectively were used for all quantitative EEG analyses).
The spectral changes in the waking EEG after drug injection were determined for artifact-free wakefulness (mean $=96.3 \pm 0.67 \%$ of recording time) occurring between the time of injection and sleep onset. EEG spectra were expressed individually as a percentage of the wakefulness spectra in the 12-h baseline light period (range: $0.75-90 \mathrm{~Hz}$; resolution: $0.25 \mathrm{~Hz}$; values between 48.25 and $51.75 \mathrm{~Hz}$ were excluded due to $50 \mathrm{~Hz}$ noise in some of the recordings). The time course of spectral EEG changes during the druginduced wakefulness was assessed by dividing this period into 12 intervals (for YKP10A and $d$-amphetamine) or 24 intervals (for modafinil) to which an equal number of 4-s waking epochs contributed within individual mice (ie, percentiles).

To further quantify the spectral changes in the waking EEG, the following frequency ranges were defined: theta: 4.75$9.75 \mathrm{~Hz}$, beta-2: $20.25-34.75 \mathrm{~Hz}$, gamma: $35.25-59.75 \mathrm{~Hz}$ (excluding $48.25-51.75 \mathrm{~Hz}$ ), and 'high-frequency': $60.25-80.0 \mathrm{~Hz}$. Mean EEG power in these frequency bands was expressed as a percentage of the EEG power reached in that band during wakefulness in the 12-h baseline light period. To quantify changes in EMG, calculated as signal variance, values were similarly expressed relative to the baseline light period. Owing to movement artifacts in the EMG, especially during the $d$-amphetamine and modafinil conditions, the EMG of several mice could not be used (YKP10A: $n=11,15$, 9; $d$-amphetamine: $n=3,2,5$; modafinil: $n=3,5,3$; for D2, $\mathrm{B} 6$, and AK were used, respectively). 
Marked changes in theta-peak frequency in the waking EEG were observed after YKP10A. The frequency at which EEG power density was maximal within the theta band was visually determined for each animal and interval. Theta power at peak frequency was calculated by averaging power in the $1 \mathrm{~Hz}$ range surrounding the individually determined theta peak $( \pm 0.5 \mathrm{~Hz})$. Theta power after drug administration was expressed as a percentage of that observed after saline injection.

Drug effects on recovery of sleep were assessed as follows. Recovery patterns for sleep time were summarized as accumulated differences from the saline condition for consecutive hours starting at light onset. REM sleep-onset latency was defined as the time elapsed between sleep onset and the first, uninterrupted REM sleep episode lasting at least $8 \mathrm{~s}$. EEG delta power during NREM sleep was calculated by averaging power density in the frequency bins from 1 to $4 \mathrm{~Hz}$. Values were individually normalized by expressing them as a percentage of the mean delta power over 4-s epochs scored as NREMS in the last $4 \mathrm{~h}$ of the baseline light period; that is the lowest average level reached during baseline. The time course of EEG delta power in NREM sleep was assessed by dividing the 12 -h period into 12 (for the baseline and the saline light periods), 8 (for light post-YKP10A/amphetamine period), 5 (for light postmodafinil period), or 6 (for the dark periods) intervals to which an equal number of 4-s epoch scored as NREM sleep contributed within individual mice.

\section{Microarray Analyses}

YKP10A and modafinil (both at $150 \mathrm{mg} / \mathrm{kg}$ ) and $d$-amphetamine $(6 \mathrm{mg} / \mathrm{kg})$ were administered at light onset. Control animals (same number for each drug) were injected with saline and sleep deprived by gentle handling for $5 \mathrm{~h}$. To minimize the confounding effect of sleep deprivation by gentle handling, saline- and drug-injected animals were observed side-by-side and each time an intervention was necessary to keep saline-injected animals awake, the same intervention also being introduced in drug-injected animals. All animals were killed by cervical dislocation, the brain was rapidly removed, frozen on dry ice, and stored at $-80^{\circ} \mathrm{C}$. RNA from whole brain was isolated and purified with the RNeasy Maxi kit (Qiagen) and DNase treated. All RNA quantities were assessed with a NanoDrop ND-1000 spectrophotometer, and the quality of RNA was controlled on Agilent 2100 Bioanalyzer chips. Experiments were performed separately for each drug and therefore control animals were repeated for each drug treatment. Equal amounts of total RNA were pooled from three mice within each of the 18 experimental groups (three strains, three drugs, and three corresponding sleep deprivations; all in biological triplicate: $18 \times 3=54$ chips). Microarray was performed as described (Maret et al, 2007). Briefly, $3 \mu \mathrm{g}$ was used for labeling. Twelve micrograms of amplified, biotinylated cRNA from each sample were fragmented and hybridized to GeneChip Mouse 4302.0 arrays. RMA normalization was performed separately for each drug treatment (Irizarry et al, 2003). For each drug treatment and each strain (nine conditions), differentially expressed features compared with sleep-deprived control (three chips $v s$ three chips) were identified using Limma (Smyth, 2004).
The moderated $t$-statistics calculated by Limma were combined in one matrix with rows (probe sets) ordered according to the variance of the moderated $t$-statistics across the nine comparisons. This procedure allows comparing the results across the three experiments. Twoway complete linkage hierarchical clustering was performed using Pearson correlation distance metric. Cluster significance was assessed using the $R$ package Pvclust (Suzuki and Shimodaira, 2006).

\section{c-FOS Immunohistochemistry}

A preliminary neuroanatomic comparative experiment between the three stimulants and saline was realized only in B6 mice to analyze the c-FOS activation pattern in brain sections $2 \mathrm{~h}$ after YKP10A, modafinil ( $150 \mathrm{mg} / \mathrm{kg}$ for both), and $d$-amphetamine $(6 \mathrm{mg} / \mathrm{kg})$ injection at light onset. Control animals were injected with saline and sleep deprived by gentle handling for $2 \mathrm{~h}$. Immunostaining experiment was performed according to Verret et al, (2005).

\section{RESULTS}

\section{YKP10A Delays Sleep Onset Without Stereotypy or Increased Locomotion}

We first assessed whether YKP10A could delay sleep onset without undesirable effects in C57BL/6J (B6) mice. During the initial dose-response experiments (Figure 1a), video and EEG recordings were carefully screened for abnormal behavior and EEG activity. Even at the highest dose $(200 \mathrm{mg} / \mathrm{kg}$ ), no signs of paroxysmal or otherwise abnormal EEG activity or stereotyped behavior were noted. Instead, mice were initially quiet while alert with eyes open responding to stimuli (mobile) and attentive without pronounced locomotor activity; this is in stark contrast to $d$-amphetamine, which, at $6 \mathrm{mg} / \mathrm{kg}$, initiated hyperactivity with stereotypic movements such as licking and repeated attempts to climb the sides of the cage. After this initial effect of YKP10A, which lasted for 30-40 min (at $150 \mathrm{mg} /$ $\mathrm{kg}$ ), activity levels returned to the levels normally associated with wakefulness.

We then compared the wake-promoting effects of the three drugs in $\mathrm{B} 6$ mice to determine an equipotent dose. YKP10A, $d$-amphetamine, and modafinil all produced dosedependent increases in the duration of EEG-defined wakefulness well beyond the waking induced by the saline control injections (Figure 1a). For both YKP10A and $d$-amphetamine, a maximal attainable response was reached within the range of concentrations tested, whereas this was not the case for modafinil. For subsequent experiments, we selected a close-to-maximum dose of 150 and $6 \mathrm{mg} / \mathrm{kg}$, for YKP10A and $d$-amphetamine, respectively, anticipating a 4to 5 -h period of sustained wakefulness. On the basis of the dose-response relationship, a $150 \mathrm{mg} / \mathrm{kg}$ dose was chosen for modafinil, anticipating a comparable wake duration.

The efficacy of these three wake-promoting drugs was compared among three inbred strains of mice; that is B6, $\mathrm{DBA} / 2 \mathrm{~J}$ (D2), and AKR/J (AK), at the doses established above for B6. In the new set of B6 mice, we could reproduce the effects of $150 \mathrm{mg} / \mathrm{kg}$ of YKP10A on sleep onset and we successfully matched this effect with a $6 \mathrm{mg} / \mathrm{kg}$ dose of 
$d$-amphetamine (Figure 1b). For modafinil, $150 \mathrm{mg} / \mathrm{kg}$ proved to be too high a dose, resulting in a $\sim 7$-h delay in sleep onset instead of the anticipated 4-5 h (compare Figure $1 \mathrm{a}$ and $\mathrm{b})$.

YKP10A and $d$-amphetamine delayed sleep onset in a similar, genotype-dependent fashion (one-way ANOVA, factor 'genotype': $\mathrm{F}_{2,54}=11.8$ for YKP10A, $\mathrm{F}_{2,19}=28.7$ for $d$-amphetamine; $P<0.0001$ for both drugs). This difference was due to B6 mice staying awake longer compared with D2 and AK mice after both drugs (Figure 1b). A similar straindistribution pattern in sleep-onset times was, however, observed after saline injections (Figure $1 \mathrm{~b}$ ). Controlling for this effect reduced the strain differences in sleep onset observed for both drugs, and B6 mice no longer differed a

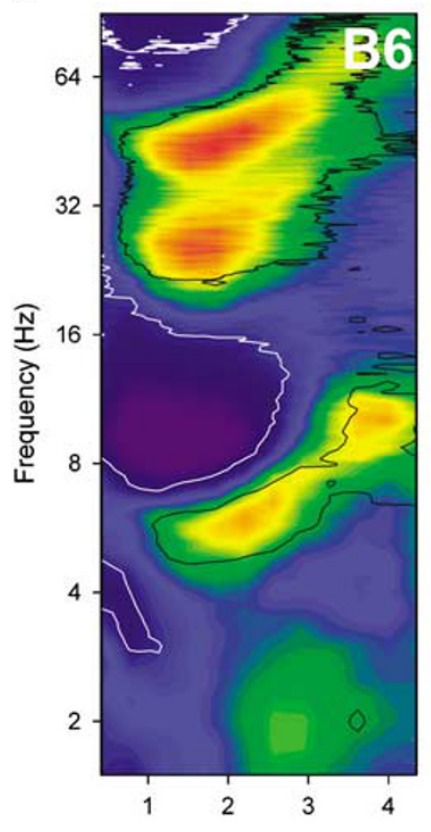

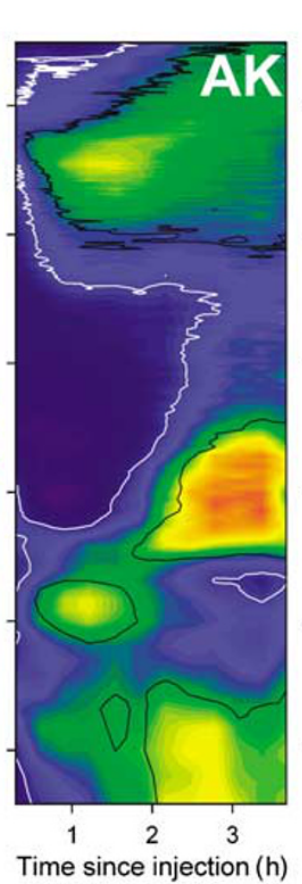

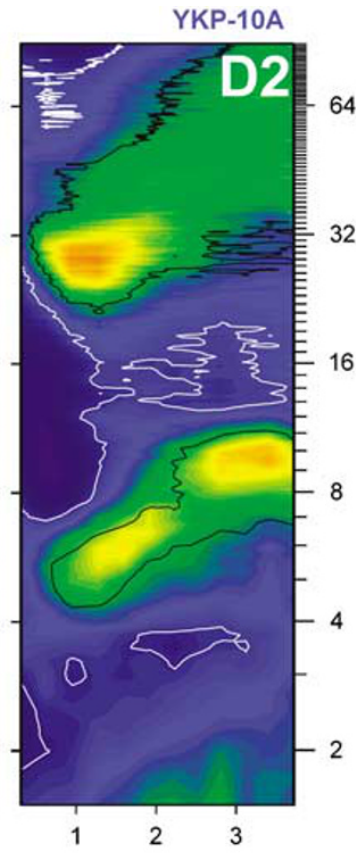

b

b Sal

d-Amphetamine
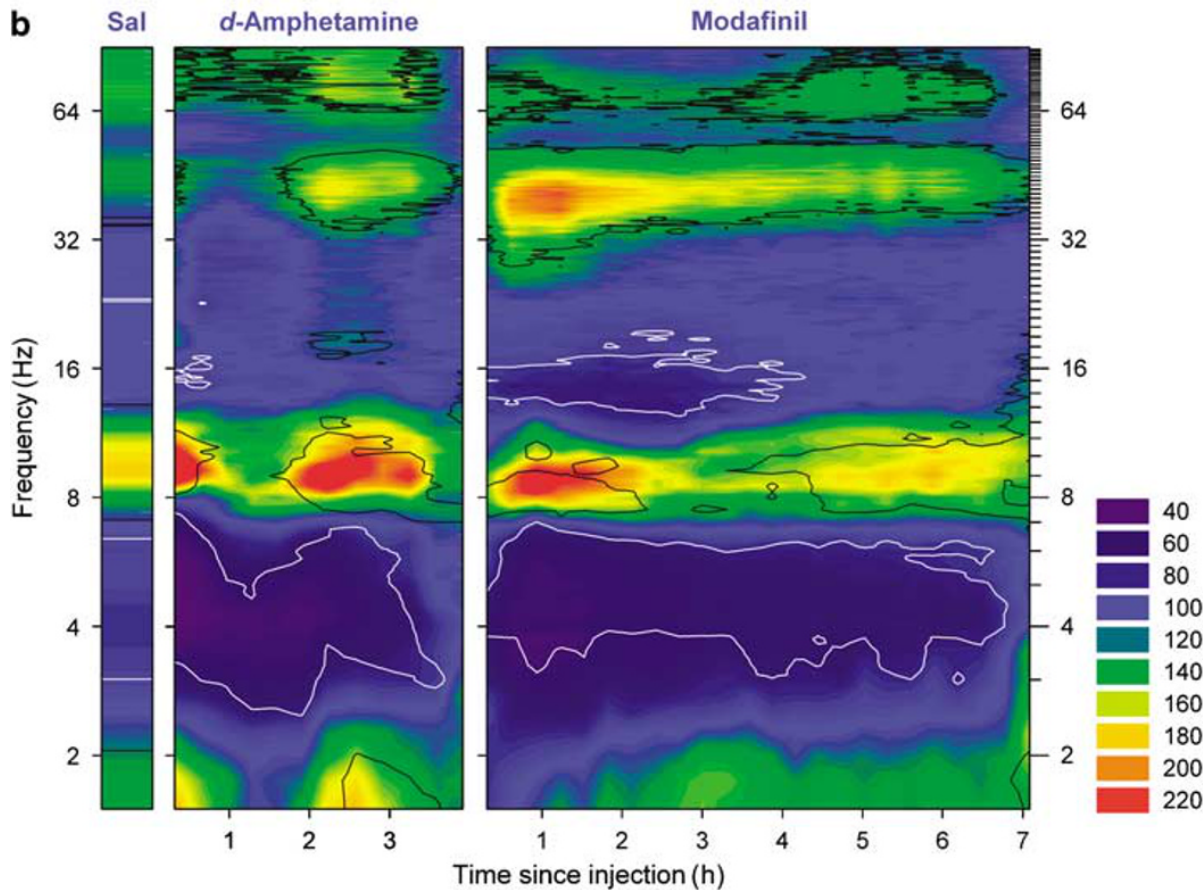

Figure 2 Time course of the effects of saline, YKPIOA, d-amphetamine, and modafinil on the EEG spectral profiles during wakefulness between time of injection and sleep onset. Mean EEG spectra within 12 (or 24 for modafinil) intervals were expressed as a percentage of the mean spectral profile for the waking EEG in the baseline light period. Changes from baseline are plotted as a heat map, with darker colors marking reduced EEG power density compared with baseline, light-blue values similar to baseline (I00\%), and warmer colors (green red) increases. (a) EEG spectral changes induced by YKPI0A in B6, AK, and D2 mice ( $n=15$ for each inbred mice). (b) EEG spectral changes induced by saline $(n=29)$, d-amphetamine $(n=6)$, and modafinil $(n=8)$ in B6 mice. Black and white contour lines delimit areas within which EEG power density was significantly decreased and increased, respectively $(P<0.0$; ; paired $t$-tests). 
from AK mice (see 'drug-saline difference' in Figure 1b). Although not significant, an opposite strain-distribution pattern was apparent for sleep-onset times after modafinil administration (one-way ANOVA; $\mathrm{F}_{2,20}=2.3, \quad P=0.12$; Figure 1b). For this drug, controlling for saline strain differences effectively increased the strain differences, and the drug-saline difference became significantly greater in AK mice compared with B6 mice (Figure 1b).

\section{Drug-Induced EEG Changes During Wakefulness}

To evaluate and compare the drug effects on the waking EEG among the three inbred strains we calculated EEG spectra over a wide frequency range $(0.75-90 \mathrm{~Hz})$ from the time of injection to sleep onset. Spectra were expressed relative to the EEG spectra of spontaneous wakefulness observed during the baseline light period (Supplementary Figure S1). Of the many significant drug and strain differences we observed, only the most salient differences will be discussed below.

Saline, $d$-amphetamine, and modafinil injections were all followed by an immediate increase in theta activity, significant in the $7-11 \mathrm{~Hz}$ range, compared with baseline (Figure 2). Increases up to threefold were observed for $d$-amphetamine and modafinil and were present for most of the time mice stayed awake. In contrast, after YKP10A administration, a profound, two- to threefold reduction in EEG activity in this frequency range was observed that lasted between 1.5 and $2.5 \mathrm{~h}$ (Figure 2). Besides this decrease that affected EEG power density in the $7-20 \mathrm{~Hz}$ range, no other changes were observed for the first two intervals (ie, $\sim 40 \mathrm{~min}$ ). One hour after YKP10A injection, an increase in theta activity appeared at the low end of the theta frequency range $(4-7 \mathrm{~Hz})$ in all three strains (Figure 2), and theta oscillations significantly slowed by $\sim 2 \mathrm{~Hz}$ compared with saline (Figure 3a). At the same time, EEG activity in the beta-2 $(20-35 \mathrm{~Hz})$ and gamma $(35-60 \mathrm{~Hz})$ frequency bands markedly increased lasting for $\sim 2 \mathrm{~h}$ (Figures 2 and $3 \mathrm{~b}$ ). Both the slowing of the theta oscillations and the increase in beta-2 activity were not observed after $d$-amphetamine or modafinil. Interestingly, the increase in beta-2 activity after YKP10A administration greatly depended on genetic background and was absent in AK mice. During the last $1-1.5 \mathrm{~h}$ of the waking period induced by YKP10A, the EEG spectra of the three strains resembled those observed after saline, $d$-amphetamine, and modafinil injections, with an elevated theta activity in the $7-11 \mathrm{~Hz}$ range and increases in EEG activity in the gamma range and even higher frequencies (' $60-80 \mathrm{~Hz}$; Figures 2 and $3 \mathrm{~b}$ ).
The high-frequency EEG changes did not seem to be confounded by changes in muscle tone. In general, the time course of the changes in EMG differed from that in the beta2, gamma, and ' $60-80 \mathrm{~Hz}$ ' frequency bands. This is best illustrated for the YKP10A experiments for which we observed profound changes in all four variables (Figure 3). YKP10A administration resulted in an immediate and profound reduction in EMG during wakefulness that gradually returned to basal levels over the course of the first $2-3 \mathrm{~h}$ after injection (Figure $3 \mathrm{c}$ ). This decrease in muscle tone coincided with the reduction in locomotor activity noted by video observations (see above). In contrast, after $d$-amphetamine, an immediate increase in EMG was observed, whereas after modafinil no change or a reduction in EMG levels could be seen.

\section{Recovery of Sleep After Drug-Induced Wakefulness}

To evaluate a wake-promoting compound it is essential to determine its impact on subsequent sleep. We therefore analyzed drug effects on recovery of sleep time lost, on EEG delta power, an index of sleep need, and on REM sleep latency (Supplementary Figure S2). The dynamics of the recovery of sleep time lost after administering the three wake-promoting drugs was analyzed by accumulating the hour-by-hour differences in sleep time between the drug and saline conditions. Thus analyzed negative slopes of accumulation reflect a loss in sleep time and positive slopes a gain relative to the saline condition (Figure 4). The comparison of the recovery patterns among the drugs was confounded by the fact that with the modafinil dose used here, animals stayed awake longer than anticipated, allowing for direct comparisons between YKP10A and $d$ amphetamine only.

Recovery patterns differed between sleep states and among drugs and strains. In general, recovery of REM sleep time varied less with strain, and recovery seemed to be regulated 'better' as compared with that of NREM sleep time insofar that REM sleep deficits were smaller $24 \mathrm{~h}$ after drug injection (Figure 4). Thus, after YKP10A administration, REM sleep recovery was complete (ie, reaching 0 level) by hour 21 for all three strains, whereas for NREM sleep, this was true only for D2 mice; that is B6 and AK mice still showed a $\sim 1$-h deficit at hour 24 with respect to the saline condition (Figure 4). Even after modafinil, despite a larger sleep loss and a shorter recovery period, recovery of REM sleep was almost complete by hour 24, whereas for NREM sleep a 1.5- to 3.5-h deficit remained. The strain differences in NREM sleep recovery observed after modafinil can to a large extend be explained by the fact that recovery sleep

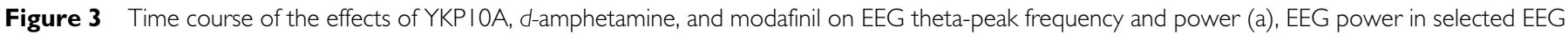

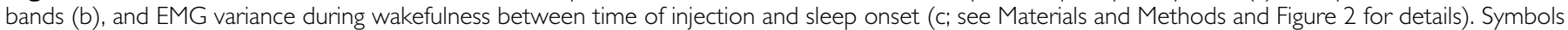

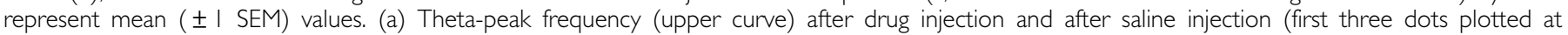

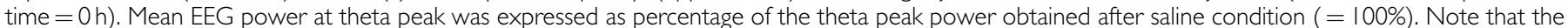

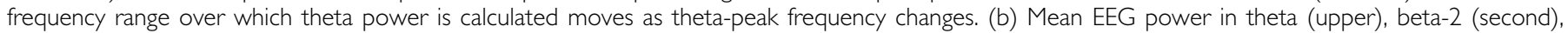

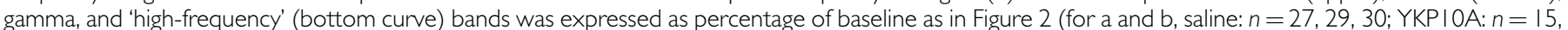

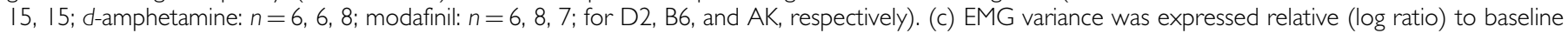
$(=0)$ (YKPIOA: $n=11,15,9$; d-amphetamine: $n=3,2,5$; modafinil: $n=3,5,3$; for D2, B6, and AK, respectively). Gray, white, and black bars at the bottom

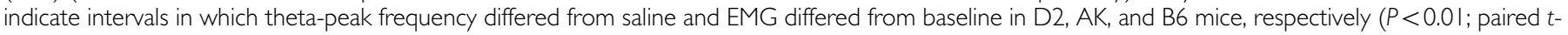

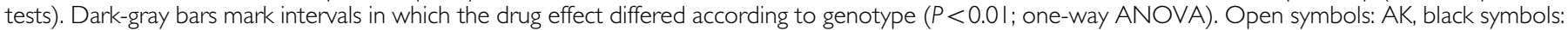
B6, gray symbols D2 mice. 
started $\sim 1 \mathrm{~h}$ earlier in B6 mice (Figure 4, see Figure 1). Interestingly, $d$-amphetamine was followed by an overcompensation of REM sleep time in all three strains and an overcompensation of NREM sleep in D2 and AK mice but not in $\mathrm{B} 6$ mice.
For all three drugs, the compensation of NREM sleep occurred mostly during the dark period. During the light period, recovery patterns differed among strains. Both after YKP10A and $d$-amphetamine, no recovery of the NREM sleep time lost was observed in B6 mice, whereas REM sleep a

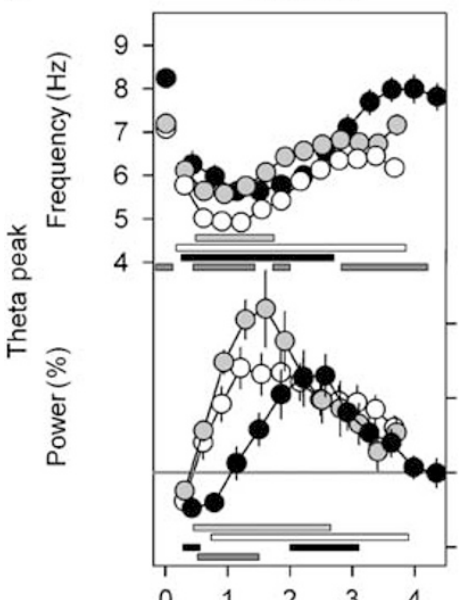

b

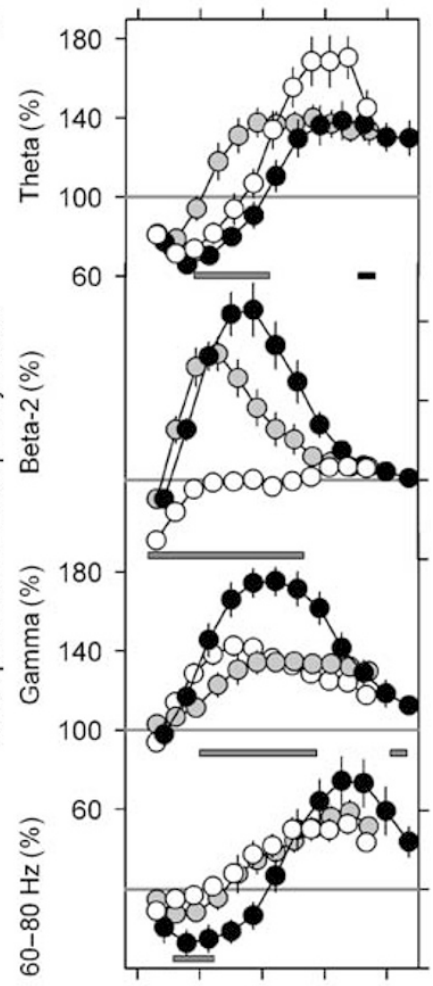

C

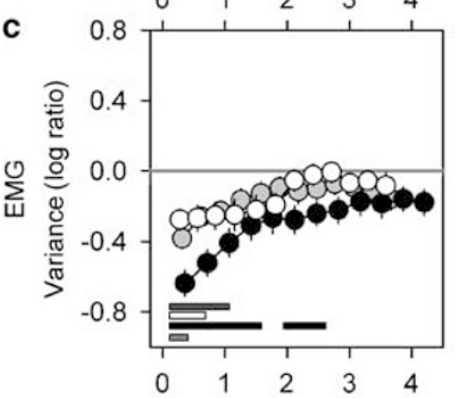

d-Amphetamine
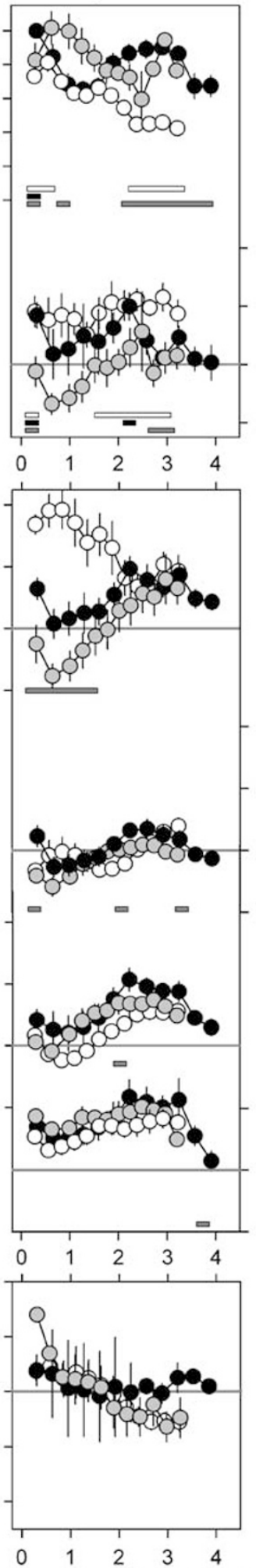

Time since injection $(\mathrm{h})$
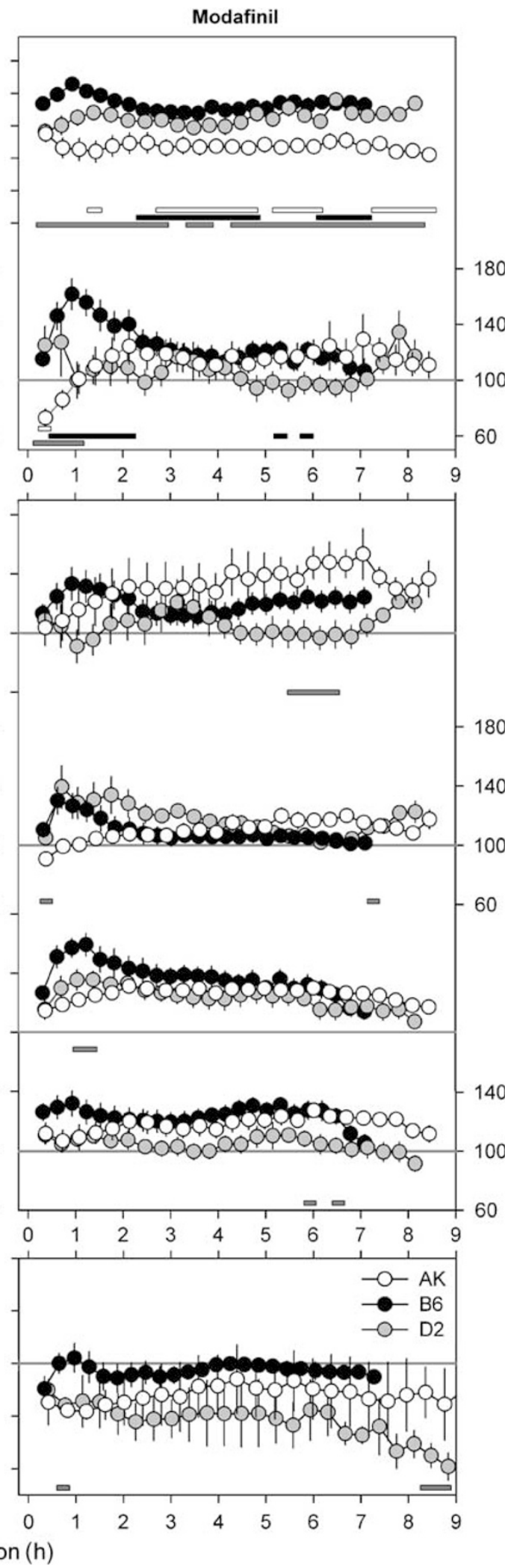

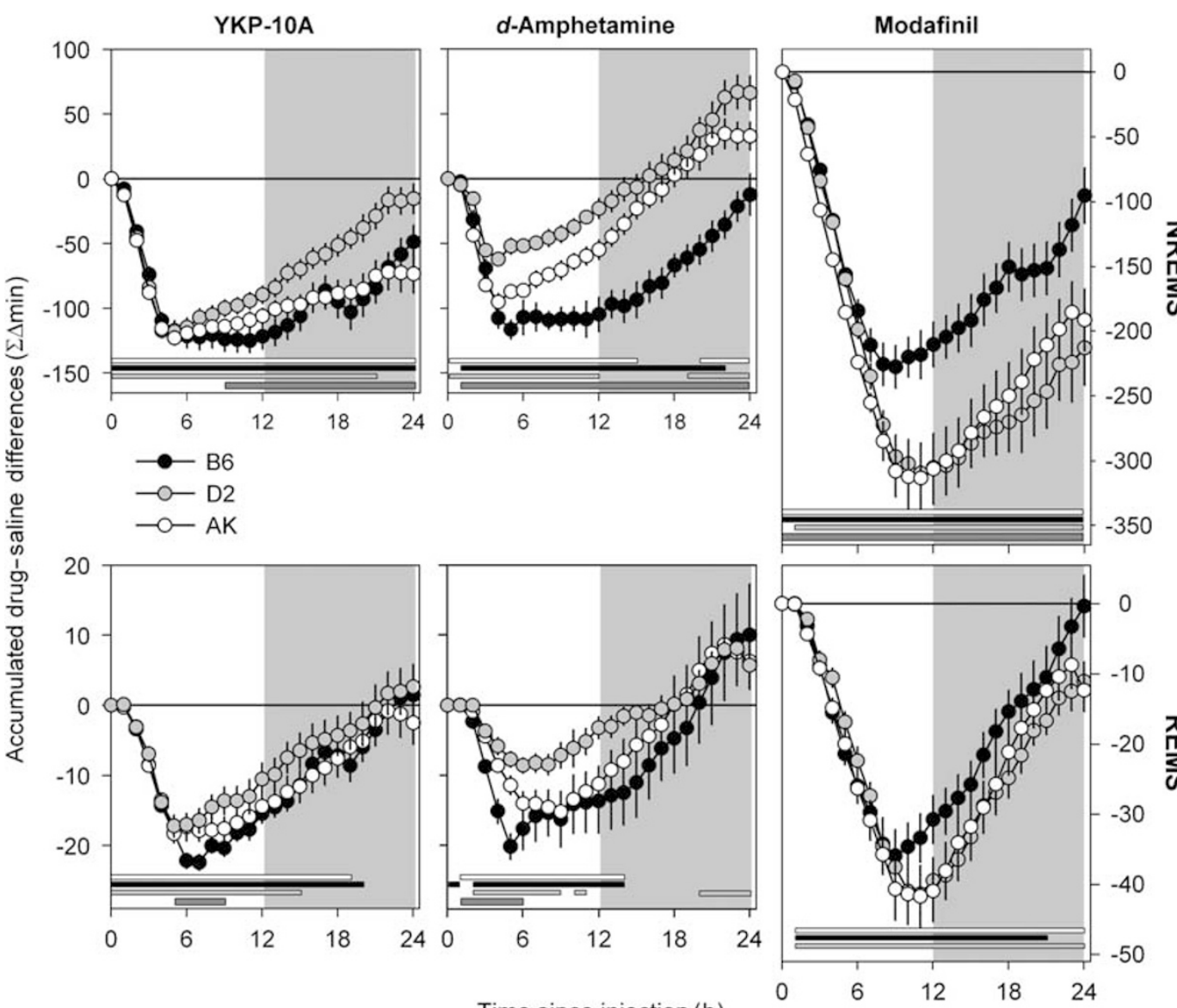

Time since injection $(h)$

Figure 4 Time course of accumulated differences in sleep time between the drug (YKP I OA, d-amphetamine, and modafinil) and saline conditions. NREMS (upper) and REMS values (lower panels; mean \pm I SEM; YKPIOA: $n=15,15,15$; d-amphetamine: $n=6,6,8$; modafinil: $n=6$, 8, 7; for D2, B6, and AK, respectively) were expressed relative to saline conditions (black horizontal line). White (AK), black (B6), and gray (D2) bars at the bottom indicate intervals in which the accumulated difference differed from saline $(P<0.05$; paired $t$-tests). Dark-gray bars mark intervals in which the drug effect differed according to genotype $(P<0.05$; one-way ANOVAs). Gray areas denote the dark period.

did increase during this period (Figure 4). During the $4-5 \mathrm{~h}$ of recovery time that remained during the light period after modafinil administration, none of the strains significantly reduced their NREM or REM sleep deficit; if at all, in D2 and AK mice, the NREM sleep deficit further increased during this period.

\section{EEG Delta Power During NREM Sleep}

EEG delta power is widely used as an index of sleep need. It is thus of interest to know whether the wakefulness induced by the three drugs affected EEG delta power in subsequent NREM sleep to the same extend. Irrespective of treatment and genotype, the level of EEG delta power showed its typical declining trend during the light periods when NREM sleep is prevalent and increased during the dark period when mice are mostly awake (Figure 5). Saline injections did not greatly impact EEG delta power although subtle changes were observed that are relevant for interpreting the drug effects (see below); in the first interval after the saline injection, EEG delta power was significantly increased relative to baseline in $\mathrm{B} 6$ mice and decreased in $\mathrm{AK}$ mice (Figure 5; statistics not shown). In addition, values in the first two intervals of the dark period were lower than baseline for B6 and D2 mice.

As expected, drug-induced wakefulness was followed by an increase in EEG delta power. YKP10A induced a higher EEG delta power in all three strains during the first four intervals after sleep onset compared with the first four intervals after sleep onset in the saline condition (Figure 5). Also, after $d$-amphetamine, an initial increase over saline was observed, but this increase was less pronounced and limited to the first interval and significant only for $\mathrm{AK}$ and $\mathrm{D} 2$ mice. The lack of an increase in B6 mice could have been due to the fact that only for this strain EEG delta power was already significantly increased after the saline injection. The relative increase in EEG delta power immediately after sleep onset did not significantly differ between the YKP10A and $d$-amphetamine conditions but later on during the light period the relative values after $d$-amphetamine were lower than after YKP10A only for AK (intervals 3, 6-7 after sleep onset; minimum $\mathrm{F}_{1,21}=4.4$ ) and $\mathrm{D} 2$ (intervals 3-4; minimum $\mathrm{F}_{1,19}=5.7, P<0.05 ; t$-tests). As EEG delta power decreases during NREM sleep, the lower relative values observed after $d$-amphetamine might be a consequence of the smaller deficit in NREM sleep time during the light period observed after $d$-amphetamine as compared with 


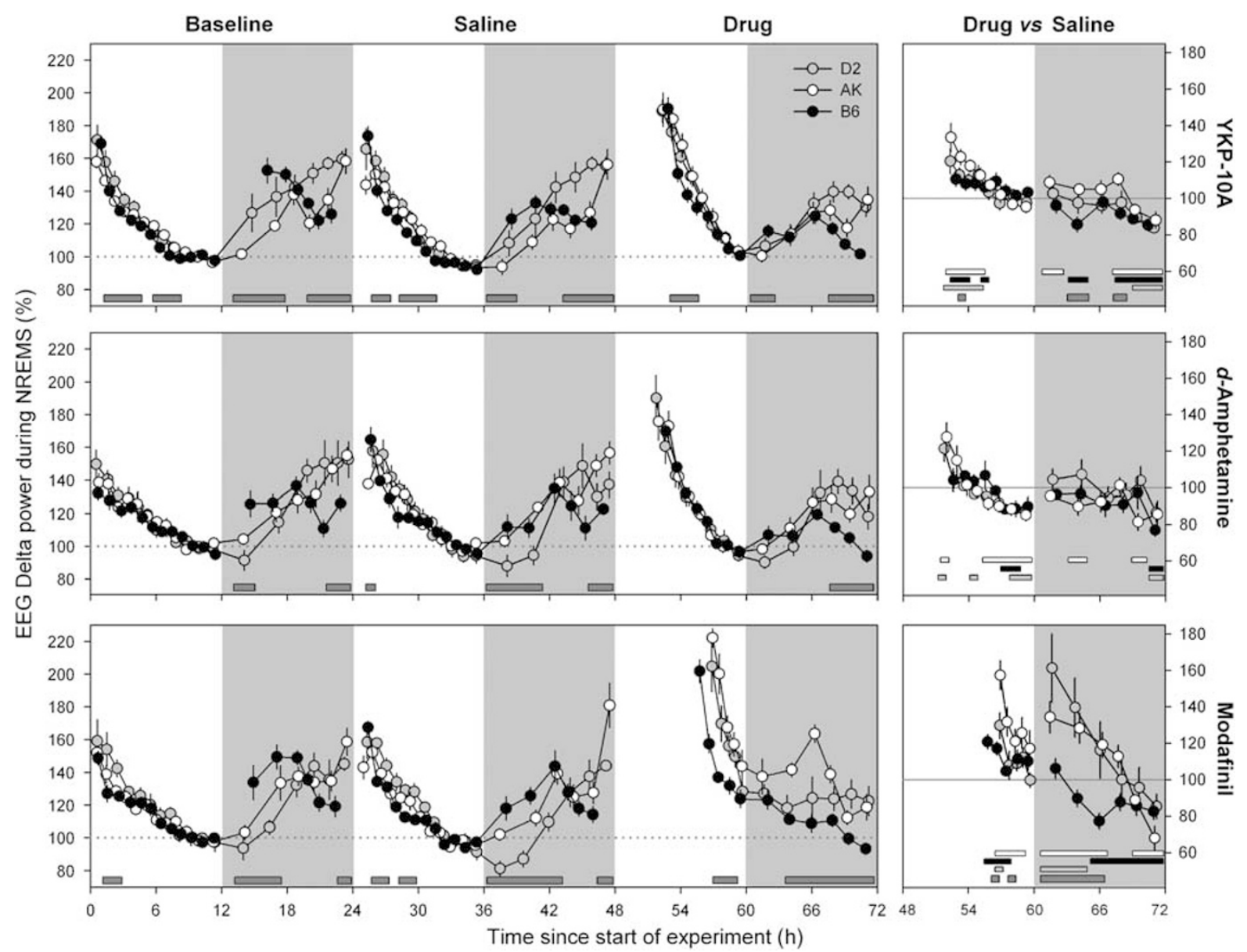

Figure 5 The effects of YKPIOA, d-amphetamine, modafinil, and saline injections on the time course of EEG delta power during NREM sleep. Left panels: EEG delta power (mean \pm I SEM; saline: $n=27,29,30$; YKPIOA: $n=15,15,15$; d-amphetamine: $n=6,6,8$; modafinil: $n=6,8,7$; for D2, B6, and AK, respectively) was expressed relative to the last $4 \mathrm{~h}$ of the baseline light period $(=100 \%)$. Dark-gray bars at the bottom of each panel mark intervals in which significant strain differences were observed ( $P<0.05$; one-way ANOVAs). Right panels: changes in EEG delta power after drug injection expressed as a percentage of the saline condition. In the light periods, corresponding intervals were compared with respect to sleep onset; in the dark period with respect to dark onset. Significant differences from saline are marked by colored bars (same color coding as in Figure 4; $P<0.05$; paired $t$-tests). Dark-gray bars indicate intervals in which the drug-saline difference differed among strains $(P<0.05$; one-way ANOVA).

YKP10A (see Figure 4). The same effect might underlie the decrease in EEG delta power below saline levels observed in the last two intervals of the dark period (Figure 5) because most of the NREM sleep time lost was compensated during this period (Figure 4). This decrease below saline levels was observed also for modafinil (Figure 5).

Modafinil caused a significant increase in EEG delta power above saline levels in all three strains (Figure 5). Consistent with the longer waking period induced by modafinil, levels reached in the first interval after sleep onset seemed higher compared with those observed after the other two drugs. Significant differences were, however, observed only for AK (modafinil vs YKP10A; $\mathrm{F}_{1,20}=4.2$ and $d$-amphetamine; $\mathrm{F}_{1,13}=12.1$ ) and for B6 (modafinil $v s$ $d$-amphetamine; $\mathrm{F}_{1,12}=12.9, P<0.05$; $t$-tests).

\section{Drug Effects on Brain Gene Expression}

The differential effects of the three wake-promoting drugs and three genotypes on brain mRNA levels were assessed by microarray analysis. It should be emphasized that the druginduced changes in gene expression reported here were contrasted to the levels reached in mice that were injected with saline and then kept awake by gentle handling for the same duration. This way, the profound changes in gene expression due to extended waking per se (Maret et al, 2007) are accounted for.

Only few of the $\sim 45000$ probe sets tested were found to be significantly affected by the drug condition (Supplementary Figure S3). The number of genes that changed expression after modafinil and YKP10A was higher for D2 compared with the other two strains. Especially, in B6 mice, very few genes changed (two and eight, respectively, $v s 50$ and 75 in D2 mice; Supplementary Figure S3). The opposite was true for $d$ amphetamine that changed two- to threefold fewer genes in D2 mice. In general, after YKP10A, the number of genes that expressed was twofold higher than for the other two drugs (Supplementary Figure S3). It should also be noted that only very few (or none for some conditions) probe sets were similarly affected by drug or genotype (Figure 3 ).

In B6 mice, $d$-amphetamine caused a significant increase in the expression of Dio2, Crem, Homerla, and the heatshock proteins Hspa1a, $-a 1 b$, and -b1 (Supplementary Table S1), confirming the earlier reports (Budziszewska 
et al, 1996; Fujiyama et al, 2003; Sokolov et al, 2003). The expression of the same set of genes was found to be increased in mice kept awake by gentle handling alone (Maret et al, 2007), suggesting that amphetamine further potentiates some of the same pathways already activated by prolonged wakefulness. In $\mathrm{AK}$ and $\mathrm{D} 2$ mice treated with amphetamine, the same genes again ranked among the most significant but, excepting Dio2, the mRNA changes failed to pass the false discovery rate (FDR) set at 5\% (Supplementary Tables S2 and S3). Of the remaining drugs, only modafinil gave significant results in D2 mice (Supplementary Table S4-S9).

The low number of genes identified, despite the large fold changes observed for some, suggests that our gene expression analysis lacks sufficient power. As a complementary approach we therefore undertook a gene signature approach using the genes with the highest variance across the nine conditions (three drugs $\times$ three strains) as markers of the effect of a particular drug in a particular strain. To determine the number of genes required to differentiate the nine conditions, we performed a sequence of hierarchical clustering using the 2000,1000,500, and 200 most variable probe sets across the nine $t$-statistic values (Figure 6a). Both bootstrap and bias-corrected probabilities were computed to assess cluster-branch strength. We observed that the conditions clustered according to drug treatment first, implying that the effect of drug on gene expression is stronger than the effect of genetic background. YKP10A treatment produced a gene expression response resembling modafinil more than $d$-amphetamine. This is particularly clear for the 'YKP10A-AK' condition that clusters either with modafinil or with the other two YKP10A conditions (ie, $\mathrm{B} 6$ and D2) depending on the number of probe sets retained for clustering. For subsequent analysis, we decided to use the 500 most variable probe sets because (i) using 2000 genes, the classification of ' $\mathrm{KKP} 10 \mathrm{~A}-\mathrm{AK}$ ' condition did not give a strong cluster probability, (ii) using 1000 genes, the 'YKP10A-AK' condition was still classified with modafinil, and (iii) using 200 genes, the overall cluster probabilities started to deteriorate.

Gene (ie, probe sets) clustering identified five main patterns of change in gene expression (Figure 6b; Supplementary Table S10). Clusters 2 and 4 were dominated by the modafinil response (cluster 2: upregulation; cluster 4: downregulation). Cluster 2 included many metabolic genes Sgk, Slc2a1, Ugt1a1, Sult1a1, Xdh, Pdk4, and others such as Fos and Cdkn1a. Glycine receptor Glra2 was present in cluster 4. Cluster 3 contained genes upregulated by $d$-amphetamine (Arc, Crem, Dio2, Homer1a, Hspa1a, Hspa1b, Hspb1, Hsp110, Insl5, Npas4, Nr4a1, and Ppp1r3c). Clusters 1 and 5 showed the most interesting patterns, with opposite effects of YKP10A and $d$-amphetamine. Moreover, in cluster 1, a strain effect was noticeable: gene expression in AK mice treated with either $d$-amphetamine or YKP10A was affected less or in the opposite direction compared with B6 and D2. Among these genes, we found the enzymes Adarb1 and Gad2 (GABA synthesis) (cluster 1), the transcription factor $D b p$ (cluster 5), which is downregulated by sleep deprivation (Franken et al, 2007; Wisor et al, 2002), and amphetamine (Sokolov et al, 2003), the ion channels, and receptors Cacna2d1, Gabrb2 (GABA-A) (cluster 1) and Oprm1, Kcnn2, Ntrk2 (cluster 5), and the signaling molecules Stxbp1, Adrbk1, Creb1 (cluster 1) and Crebbp, Pten, and Vtila (cluster 5).

\section{Phenotype-Gene Expression Correlations}

In an effort to link gene expression with physiology, we used the nine strain $\times$ drug conditions and correlated gene expression-moderated $t$-statistic values with the most salient drug-dependent changes in the waking EEG; that is the relative changes in EEG power in the theta, beta-2, and gamma frequency bands during the time that showed the largest difference among drugs (ie, the first 2- to $2.5-\mathrm{h}$ period after drug injection). We observed that cluster 1 genes tend to correlate negatively and cluster 5 genes positively with beta-2 activity (Figure $6 \mathrm{c}$ ). Among the genes that correlated negatively, we found syntaxin-binding protein 1 (Stxbp1; $r=-0.80)$ and adenosine deaminase, RNA-specific, B1 (Adarb1; $r=-0.82$ ), which is known to be involved in the editing of the pre-mRNA of glutamate receptor B subunit (Mittaz et al, 1997). Among those that correlated positively, we found neurocan (ncan; $r=0.88$ ) and NMDA receptor-regulated 1-like (Narg1l; $r=0.85$ ) (Supplementary Table S10). Only eight probe sets were significantly correlated with changes in EEG gamma activity. Among those, we found Slc7a10 (also known as Asc- $1 ; r=0.81$, which is involved in controlling hyperexcitability (Xie et al, 2005). Almost all significant probe sets were negatively correlated with theta activity and belong to cluster 5, such as Narg1l $(r=-0.91)$, Dnajb14 (Hsp40) $(r=-0.82)$, and $G s k 3 b(r=-0.81)$, a cell-proliferation gene associated with antidepressant treatment response (Tsai et al, 2008). It should be noted that the EEG measurements for theta and beta-2 activity were negatively correlated $(r=-0.64)$, and thus probe sets that correlated with one tended to show an opposite correlation with the other.

\section{Drug-Induced c-FOS Activity}

We examined c-FOS induction in the brain to assess whether among the three drugs common neuronal pathways were implicated in wake promotion. c-FOS immunoreactivity

\footnotetext{
Figure 6 Comparative transcriptome analysis indicates that YKPIOA (YKP) is affected more by genetic background than amphetamine and modafinil $(n=9$ for each drug and strain, $n=9$ for each control and strain). (a) Hierarchical clustering of the nine drugs vs saline comparisons using the 2000, 1000,500 , or 200 most variable probe sets. Moderated $t$-statistic data were used for clustering analysis, as outlined in Materials and Methods. The bootstrap probability value (green) and the approximately unbiased probability values are indicated for each cluster. (b) Two-way hierarchical clustering of the 500 most variable probe sets and the nine drug vs saline conditions. Probe sets are grouped in five clusters (Cl. I-5). Red: positive t-statistic; green: negative t-statistic. (c) Left panel: correlation coefficient $(r)$ between the moderated t-statistic values for the 500 most-variable probe sets and EEG power in the frequency bands beta-2, gamma, and theta, using the nine strain $\times$ drug conditions as samples. Red: positive correlation; green: negative correlation. Genes are ordered as in the clustering analysis. Right panel: genes with significant correlations (Pearson's correlation test, $P<0.0 \mathrm{I}$ ) with one of the three phenotypes indicated with white bands.
} 
was determined in brain sections from B6 mice killed $2 \mathrm{~h}$ after drug administration. Amphetamine and modafinil induced c-FOS in similar brain regions but at different levels (Supplementary Figure S4). The cerebral cortex was activated more by amphetamine (especially clear in the piriform, somatosensory, motor, and cingulate cortex), whereas other regions such as the dentate gyrus, dorsomedial hypothalamus, and amygdale were equally affected. The striatum was clearly activated more after modafinil administration. Moreover, also the hippocampal CA1 and CA3
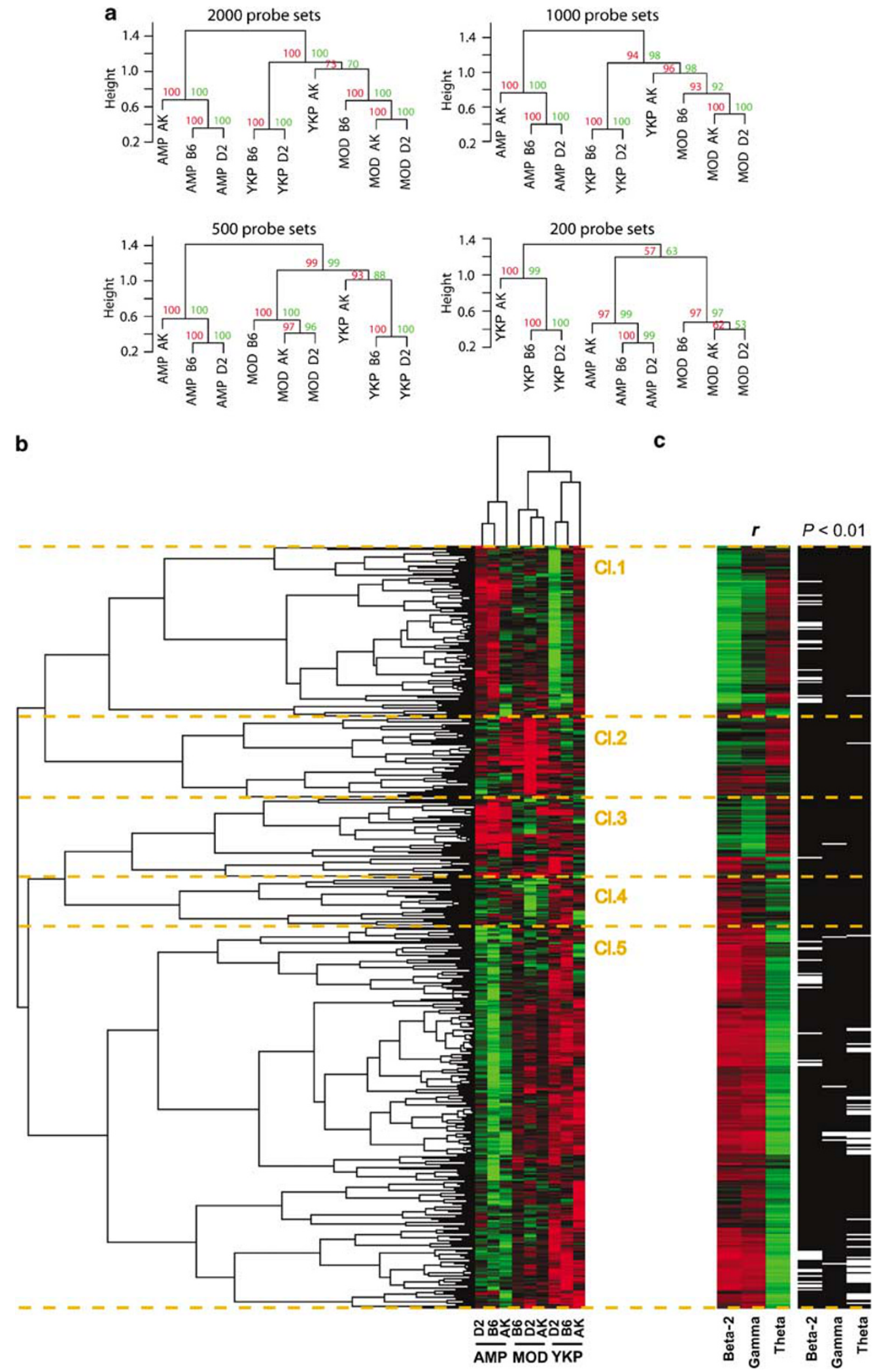
regions seemed to be activated more. In the ventromedial hypothalamus, paraventricular thalamus, periaqueductal gray, substantia nigra, and lemniscus, c-FOS was induced by amphetamine, specifically while the vertical limb of the diagonal band, accumbens (shell), and pallidum were activated only after modafinil. As opposed to the two other stimulants, YKP10A did not induce c-FOS in the striatum, whereas more activated neurons were observed in the hippocampus (in the CA1 area, specifically; see Supplementary Figure S4). YKP10A and modafinil shared many areas of similar activation such as the lateral septal nucleus, the septohippocampal nucleus, the dorsal tenia tecta, the seminular nucleus, the island of calleja, the olfactory tubercle, and the arcuate nucleus. The subiculum, ventral tenia tecta, the nucleus of solitary tract gelatinous, dorsal endopiriform, and suprachiasmatic nucleus were activated by YKP10A, specifically.

\section{DISCUSSION}

We have compared the EEG activity and brain geneexpression 'signatures' of three wake-promoting compounds in inbred strains of mice for which the expression and regulation of sleep and wakefulness differed greatly (Franken et al, 2001). The specific EEG and brain geneexpression signatures were determined primarily by drug and then modified by genetic background. The c-FOS immunoreactivity results confirmed that drugs greatly differ in the structures they target, which was especially clear in the cerebral cortex, hippocampus, and striatum. Taken together, this broad range of findings underscores the notion that various pathways can be activated pharmacologically to maintain the brain awake. In addition, these EEG and gene-expressing findings also indicate that the wakefulness induced by the three compounds differed in quality as confirmed by behavioral observations. Finally, irrespective of the pathways activated to delay sleep onset and the type of wakefulness induced, all three compounds induced an increased sleep drive that, for $d$-amphetamine, even resulted in an overcompensation of sleep time.

\section{Drug Effects on the Waking EEG}

We demonstrated that the waking EEG profiles following $d$-amphetamine and modafinil administration were similar corroborating observations in the cat (Lin et al, 2000, but see also Chapotot et al, 2003). The most salient EEG changes concerned an increase in both power and frequency of theta oscillations and an increase in gamma activity. These EEG changes differed markedly from those induced by YKP10A, which was followed by a pronounced slowing of theta oscillations and a reduction in EEG power in the $7-20 \mathrm{~Hz}$ range, concomitant with an increase in gamma activity. Gamma activity is often associated with the presence of theta oscillations in rodents (Sainsbury, 1998), but YKP10A seems to dissociate these two types of EEG activities. A similar theta-slowing concomitant with an induction of gamma was observed after administering the muscarinic agonist oxotremorine in rats (Timofeeva and Gordon, 2001). The gradual and transitory slowing of theta oscillations that followed YKP10A might thus result from a continuum of increasing activation of additive drives from the brainstem and from cholinergic sources as suggested by Vertes and Kocsis (1997).

YKP10A also induced a specific increase in beta- 2 activity not observed with the other drugs. Pronounced increases in beta oscillations have also been observed after dopamine depletion in the rat (Sharott et al, 2005). This increase in beta-2 activity combined with YKP10A's clinical profile that resembled that of the drugs known to affect dopamine transmission and preliminary in vitro results (see Introduction) thus lends further support to the notion that this compound affects dopamine signaling. Activity in the beta frequency range seems also to be negatively correlated with voluntary movements in humans (Kuhn et al, 2004) consistent with the pronounced reduction in locomotor activity observed shortly after the injection in this study. YKP10A administration could not elicit beta-2 activity in AK mice, whereas the slowing of theta was also observed in this strain.

Although in most pharmacology studies, the waking EEG is quantified up to $30 \mathrm{~Hz}$ only, here we could demonstrate that all three drugs induced gamma and even higher ' $60-$ $80 \mathrm{~Hz}$ ' EEG activities. In freely moving rats, these highfrequency activities showed an association with waking and REM sleep (Franken et al, 1994) and spontaneous behaviors (Maloney et al, 1997). The ' $60-80 \mathrm{~Hz}$ ' EEG activity might be related to the series of fast $(60-115 \mathrm{~Hz})$ hippocampal population spikes or 'high' gamma (Pais et al, 2003; Traub et al, 2001). These high-frequency components have been reported to be associated with the presentation of meaningful stimuli, with attentional processes and voluntary movements, and have been suggested to represent a correlate of cognition and synaptic plasticity (Canolty et al, 2006; Crone et al, 2006; Gray and Singer, 1989; Sanes and Donoghue, 1993; Tiitinen et al, 1993; Traub et al, 2005). The enhanced gamma activity observed during druginduced wakefulness might thus reflect heightened cognitive performance and, at least for modafinil, an increase in working memory has been demonstrated in mice (Beracochea et al, 2001, 2002, 2003; Pierard et al, 2006) and rats (Miller et al, 2000; Ward et al, 2004). Other corroborating observations come from the increased c-FOS activity in the hippocampus of B6 mice, which was largest for the drug that also induced the largest increase in gamma activity; that is YKP10A. Gamma activity in the hippocampus is thought to coordinate CA3 and CA1 networks during memory task performance (Montgomery and Buzsaki, 2007) in which c-FOS reactivity was exclusively found.

\section{Effects on Sleep Following Drug-Induced Waking}

The waking induced by all three drugs was followed by a compensatory rebound in both duration and intensity (ie, EEG delta power), indicating that sleep homeostatic mechanisms were activated irrespective of the differences the drug induced in EEG activity or gene expression. Ideally, a wake-promoting compound should promote wakefulness without rebound hypersomnolence. In this respect, $d$-amphetamine's performance is especially poor as an 'overcompensation' of sleep time was observed for both REM and NREM sleep. A similar overcompensation has been already reported for REM sleep after $d$-methylamphetamine 
administration (Kitahama and Valatx, 1979). An overcompensation of NREM sleep has not been reported earlier and was due to the fact that recovery started immediately after sleep onset, whereas after YKP10A and modafinil, the recovery was delayed and started after dark onset only. Again a marked strain difference was observed; for B6 mice, the usual delay in recovery of NREM sleep time was also present under $d$-amphetamine conditions. Similar drug differences in the sleep recovery dynamics have been reported in rats in which the effects of amphetamine and modafinil were compared (Edgar and Seidel, 1997; Wisor et al, 2006). In contrast to our study, other studies in rats (Touret et al, 1995) and cats (Lin et al, 2000) did, however, not find evidence for rebound sleep after modafinil, which added to the interest in this drug as a wake-promoting agent.

Similarly, an increase in EEG delta power during NREM sleep, an index of sleep need and depth or intensity of NREM sleep, compared with the levels reached after saline, was observed for most conditions and strains. In mice, the EEG delta power rebound after modafinil administration did not differ from the increase observed after manual sleep deprivation of the same duration (Kopp et al, 2002), indicating that the sleep homeostatic mechanisms are similarly activated in both conditions. This was confirmed also in rats (Edgar and Seidel, 1997), whereas in that study, methylamphetamine did not elicit a significant rebound. The modafinil- $d$-amphetamine comparison in this study was confounded by the longer duration of waking induced by modafinil. The YKP10A-d-amphetamine comparison indicated, however, that also in our study amphetamine induces a less robust and shorter lasting increase in EEG delta power and, similar to the rat study, no significant increase was observed in B6 mice. Finally, also in humans, slow-wave sleep duration, that is the fraction of NREM sleep with high levels of EEG delta power, was significantly increased after modafinil and sleep deprivation, but not after amphetamine (Buguet et al, 1995). This different response after $d$-amphetamine could indicate that because EEG delta power increased to a lesser extent, the increased sleep need was coped with by sleeping longer (overcompensation).

The drug-dependent effects of wakefulness on subsequent EEG delta power are of interest in the context of sleep function. One prominent hypothesis on sleep function poses that sleep plays a role in synaptic homeostasis by countering ('down-scaling') the synaptic strengthening imposed by wakefulness. More specifically, down-scaling could be functionally related to the expression of EEG delta oscillations (reviewed by Tononi and Cirelli, 2006). Accordingly, EEG delta power is increased more after longer and/or more intense waking periods, such as periods of exploratory behavior, as was reported in rats (Huber et al, 2007). Given this, the behavioral quiescence and marked suppression of theta activity after YKP10A administration should have been followed by only a modest EEG delta increase, whereas the hyperactivity and pronounced theta activation following $d$-amphetamine should have been followed by a higher rebound. However, in this study, the opposite is found suggesting either that beta or gamma activity might be more relevant in inducing synaptic strength (as they were induced more by YKP10A) or that $d$-amphetamine could interfere with the expression of EEG delta oscillations even after sleep onset.

\section{Effect on Brain Gene Expression}

Psychostimulants affect the expression of immediate early genes, such as Fos, Arc, and Homerla, the most (Berke and Hyman, 2000; Yano and Steiner, 2007). We have shown earlier that the increase in the expression of the same genes ranks among the highest after extended wakefulness (Maret et al, 2007), raising the possibility that changes in gene expression reported for these compounds are mediated through the induced wakefulness and not specific to the drug. Although we quantified expression in whole-brain homogenates, the pronounced FOS reactivity in the striatum after modafinil administration seems consistent with a specific role of this structure in wake promotion and attention (Willuhn et al, 2003; Yano and Steiner, 2005a, b). The induction of c-FOS was, however, not observed after the other two compounds.

Whole-brain gene-expression profiling suffers many limitations, the most important being the lack of power to detect subtle but functionally significant changes in small brain regions (see discussion in Maret et al, 2007). However, sampling specific brain regions without established evidence for their involvement might also present the risk of missing valuable information from unsuspected brain regions. Moreover, Cirelli et al (2004) have reported similarities in gene expression as a function of vigilance states between the cortex (site of the EEG correlates) and the cerebellum (with no major contribution to sleep), suggesting more global than local effects of sleep and wakefulness on brain gene expression.

Our cluster analysis revealed several interesting genes or gene pathways characterizing each stimulant. Cluster 2 contained transcripts that were mostly increased by modafinil. Several of those are implicated in metabolism (see Results), supporting the role of modafinil in activating brain metabolism (Pierard et al, 1995). Another pathway identified concerned genes implicated in apoptosis (ie, Ccnd3, Cdkn1a, Ddit4, Emilin2, Fos, Klf4, Lcn2, Mgp, Nfkbia, S100a8, S100a9, Sgk1, Slc2a1, Tgm2, Txnip, Xdh, and Zbtb16; in-silico pathway analysis; Ingenuity Systems Inc.: $\left.P=3.8 \times 10^{-8}\right)$. One representative apoptotic gene is Cdkn1a (P21), a regulator of cell-cycle progression and related to stress response (Rodriguez and Meuth, 2006). Cluster 5, characterized mostly by genes overexpressed by YKP10A, included six genes (ie, Crebbp, Gsk3b, Ncan, Ntrk2, Ptprd, and Vldlr) that were positively correlated with beta-2 and/or gamma activity, and negatively correlated with theta. These genes are implicated in long-term potentiation (LTP; Ingenuity Systems Inc.: $\left.P=6.3 \times 10^{-4}\right)$. Ntrk2, the receptor that binds BDNF, is well known to be implicated in hippocampal LTP and synaptic plasticity (Gartner et al, 2006; Nagappan et al, 2008; Santi et al, 2006; Tanaka et al, 2008) and EEG delta power during recovery from sleep deprivation (Faraguna et al, 2008; Hairston et al, 2004). Together with the pronounced induction in EEG gamma activity and increase in hippocampal FOS, the changes in the expression of these genes indicate that YKP10A might modulate memory processes and cognitive performance. Stimulant-induced gene expression may also have 
detrimental impacts on behavior and/or EEG activity. The $\mathrm{Na}^{+}$-independent alanine-serine-cysteine transporter 1 Slc7a10 (Asc-1) is downregulated in our study by amphetamine in all strains. Loss of function of this gene in mice induces tremors and seizures (Xie et al, 2005). It is well known that acute, high doses of several classical stimulants including amphetamines cause seizures in mice, rats, and humans (Golden et al, 2001; Hanson et al, 1999; Zagnoni and Albano, 2002). As a cautionary note we like to point out that the analyses presented here are based on microarray data, and the changes in expression for specific genes were not independently confirmed with, for example, qRT-PCR. Nevertheless, because our gene signature approach considered only those genes that changed the most and because we have shown that the most significant changes detected by microarray analysis are routinely confirmed by qRT-PCR (Maret et al, 2007), we feel confident about the gene pathway we identified. For the same reason, the gene expression-EEG phenotype correlations should be interpreted with caution. In addition, as is the case with any correlation, the analyses do not prove causality.

\section{CONCLUSION}

We conclude that different stimulants leave different behavioral, sleep, EEG, and brain gene-expression signatures, indicating that complex molecular and neuronal pathways differentially and/or in combination are required to keep the brain awake. YKP10A is an atypical wakepromoting drug that may prove to be a useful medication in humans. It's mode of action differs greatly from that of both $d$-amphetamine and modafinil. This study also underscores that taking genetic background and the gene-expression signature into account is paramount to estimate drug efficacy in a therapeutic discovery process, especially for sleep-wake phenotypes in which genetic factors play an important role.

\section{ACKNOWLEDGEMENTS}

We thank V Calpini, S Tawffik, $\mathrm{K}$ Harshman, and O Hagenbuchle, and the staff of the Lausanne DNA array facility for their expert technical assistance. This study was supported by a research grant from Johnson and Johnson, Beerse, Belgium, and the University of Lausanne, Switzerland.

\section{DISCLOSURES/CONFLICT OF INTEREST}

MT declares that over the past 3 years he has received compensation from UCB Pharma and Servier. AA and WD declare their full-time employment at Johnson and Johnson, Pharmaceutical Research and Development, Beerse, Belgium. SH, SP, and PF declare that, except for income received from their primary employers, no financial support or compensation has been received from any individual or corporate entity over the past 3 years of research or professional service, and they have no personal financial holdings that could be perceived as constituting a potential conflict of interest.

\section{REFERENCES}

Alles GA (1933). The comparative physiological actions of $d$ 1-beta-phenyllisopropylamines: pressor effects and toxicity. J Pharmacol Exp Ther 47: 339-354.

Alsene K, Deckert J, Sand P, de Wit H (2003). Association between A2a receptor gene polymorphisms and caffeine-induced anxiety. Neuropsychopharmacology 28: 1694-1702.

Amsterdam JD, Brunswick DJ, Hundert M (2002). A single-site, double-blind, placebo-controlled, dose-ranging study of YKP10A-a putative, new antidepressant. Prog Neuropsychopharmacol Biol Psychiatry 26: 1333-1338.

Ballon JS, Feifel D (2006). A systematic review of modafinil: potential clinical uses and mechanisms of action. J Clin Psychiatry 67: 554-566.

Barbier AJ, Berridge C, Dugovic C, Laposky AD, Wilson SJ, Boggs J et al (2004). Acute wake-promoting actions of JNJ-5207852, a novel, diamine-based $\mathrm{H} 3$ antagonist. $\mathrm{Br} J$ Pharmacol 143: 649-661.

Bastuji H, Jouvet M (1988). Successful treatment of idiopathic hypersomnia and narcolepsy with modafinil. Prog Neuropsychopharmacol Biol Psychiatry 12: 695-700.

Beracochea D, Cagnard B, Celerier A, le Merrer J, Peres M, Pierard C (2001). First evidence of a delay-dependent working memoryenhancing effect of modafinil in mice. NeuroReport 12: 375-378.

Beracochea D, Celerier A, Borde N, Valleau M, Peres M, Pierard C (2002). Improvement of learning processes following chronic systemic administration of modafinil in mice. Pharmacol Biochem Behav 73: 723-728.

Beracochea D, Celerier A, Peres M, Pierard C (2003). Enhancement of learning processes following an acute modafinil injection in mice. Pharmacol Biochem Behav 76: 473-479.

Berke JD, Hyman SE (2000). Addiction, dopamine, and the molecular mechanisms of memory. Neuron 25: 515-532.

Bonaventure P, Letavic M, Dugovic C, Wilson S, Aluisio L, Pudiak $\mathrm{C}$ et al (2007). Histamine $\mathrm{H} 3$ receptor antagonists: from target identification to drug leads. Biochem Pharmacol 73: 1084-1096.

Boutrel B, Koob GF (2004). What keeps us awake: the neuropharmacology of stimulants and wakefulness-promoting medications. Sleep 27: 1181-1194.

Budziszewska B, Jaworska-Feil L, Lason W (1996). The effect of repeated amphetamine and cocaine administration on adrenal, gonadal and thyroid hormone levels in the rat plasma. Exp Clin Endocrinol Diabetes 104: 334-338.

Buguet A, Montmayeur A, Pigeau R, Naitoh P (1995). Modafinil, damphetamine and placebo during $64 \mathrm{~h}$ of sustained mental work. II. Effects on two nights of recovery sleep. J Sleep Res 4: 229-241.

Canolty RT, Edwards E, Dalal SS, Soltani M, Nagarajan SS, Kirsch HE et al (2006). High gamma power is phase-locked to theta oscillations in human neocortex. Science 313: 1626-1628.

Chapotot F, Pigeau R, Canini F, Bourdon L, Buguet A (2003). Distinctive effects of modafinil and d-amphetamine on the homeostatic and circadian modulation of the human waking EEG. Psychopharmacology (Berl) 166: 127-138.

Cirelli C, Gutierrez CM, Tononi G (2004). Extensive and divergent effects of sleep and wakefulness on brain gene expression. Neuron 41: 35-43.

Crone NE, Sinai A, Korzeniewska A (2006). High-frequency gamma oscillations and human brain mapping with electrocorticography. Prog Brain Res 159: 275-295.

Crowley JJ, Brodkin ES, Blendy JA, Berrettini WH, Lucki I (2006). Pharmacogenomic evaluation of the antidepressant citalopram in the mouse tail suspension test. Neuropsychopharmacology 31: 2433-2442.

Dauvilliers Y, Neidhart E, Billiard M, Tafti M (2002). Sexual dimorphism of the catechol-O-methyltransferase gene in narcolepsy is associated with response to modafinil. Pharmacogenomics J 2: 65-68. 
Edgar DM, Seidel WF (1997). Modafinil induces wakefulness without intensifying motor activity or subsequent rebound hypersomnolence in the rat. J Pharmacol Exp Ther 283: 757-769.

Faraguna U, Vyazovskiy VV, Nelson AB, Tononi G, Cirelli C (2008). A causal role for brain-derived neurotrophic factor in the homeostatic regulation of sleep. J Neurosci 28: 4088-4095.

Flanagin BA, Cook Jr EH, de Wit H (2006). An association study of the brain-derived neurotrophic factor Val66Met polymorphism and amphetamine response. Am J Med Genet B Neuropsychiatr Genet 141: 576-583.

Franken P, Chollet D, Tafti M (2001). The homeostatic regulation of sleep need is under genetic control. J Neurosci 21: 2610-2621.

Franken P, Dijk DJ, Tobler I, Borbély AA (1994). High-frequency components of the rat electrocorticogram are modulated by the vigilance states. Neurosci Lett 167: 89-92.

Franken P, Malafosse A, Tafti M (1998). Genetic variation in EEG activity during sleep in inbred mice. Am J Physiol 275(4 Part 2): R1127-R1137.

Franken P, Malafosse A, Tafti M (1999). Genetic determinants of sleep regulation in inbred mice. Sleep 22: 155-169.

Franken P, Thomason R, Heller HC, O'Hara BF (2007). A noncircadian role for clock-genes in sleep homeostasis: a strain comparison. BMC Neurosci 8: 87.

Fujiyama K, Kajii Y, Hiraoka S, Nishikawa T (2003). Differential regulation by stimulants of neocortical expression of mrt1, arc, and homerla mRNA in the rats treated with repeated methamphetamine. Synapse 49: 143-149.

Gartner A, Polnau DG, Staiger V, Sciarretta C, Minichiello L, Thoenen $\mathrm{H}$ et al (2006). Hippocampal long-term potentiation is supported by presynaptic and postsynaptic tyrosine receptor kinase B-mediated phospholipase Cgamma signaling. J Neurosci 26: 3496-3504.

Golden GT, Ferraro TN, Smith GG, Snyder RL, Jones NL, Berrettini WH (2001). Acute cocaine-induced seizures: differential sensitivity of six inbred mouse strains. Neuropsychopharmacology 24: 291-299.

Gordon R, Bernard P, Pack E, Lee K, Choi YM (1998). Pharmacological profile of YKP10A: a novel antidepressant. Soc Neurosci Abs 583: 24.

Gray CM, Singer W (1989). Stimulus-specific neuronal oscillations in orientation columns of cat visual cortex. Proc Natl Acad Sci USA 86: 1698-1702.

Hairston IS, Peyron C, Denning DP, Ruby NF, Flores J, Sapolsky $\mathrm{RM}$ et al (2004). Sleep deprivation effects on growth factor expression in neonatal rats: a potential role for BDNF in the mediation of delta power. J Neurophysiol 91: 1586-1595.

Hanson GR, Jensen M, Johnson M, White HS (1999). Distinct features of seizures induced by cocaine and amphetamine analogs. Eur J Pharmacol 377: 167-173.

Huber R, Tononi G, Cirelli C (2007). Exploratory behavior, cortical BDNF expression, and sleep homeostasis. Sleep 30: 129-139.

Irizarry RA, Hobbs B, Collin F, Beazer-Barclay YD, Antonellis KJ, Scherf U et al (2003). Exploration, normalization, and summaries of high density oligonucleotide array probe level data. Biostatistics 4: 249-264.

Kitahama K, Valatx JL (1979). Strain differences in amphetamine sensitivity in mice. II. Overcompensation of paradoxical sleep after deprivation in two C57 strains. Psychopharmacology (Berl) 66: $291-295$

Kopp C, Petit JM, Magistretti P, Borbely AA, Tobler I (2002). Comparison of the effects of modafinil and sleep deprivation on sleep and cortical EEG spectra in mice. Neuropharmacology 43: 110-118.

Kuhn AA, Williams D, Kupsch A, Limousin P, Hariz M, Schneider $\mathrm{GH}$ et al (2004). Event-related beta desynchronization in human subthalamic nucleus correlates with motor performance. Brain 127(Part 4): 735-746.
Lin JS, Gervasoni D, Hou Y, Vanni-Mercier G, Rambert F, Frydman A et al (2000). Effects of amphetamine and modafinil on the sleep/wake cycle during experimental hypersomnia induced by sleep deprivation in the cat. $J$ Sleep Res 9: 89-96.

Lott DC, Kim SJ, Cook Jr EH, de Wit H (2005). Dopamine transporter gene associated with diminished subjective response to amphetamine. Neuropsychopharmacology 30: 602-609.

Maloney KJ, Cape EG, Gotman J, Jones BE (1997). High-frequency gamma electroencephalogram activity in association with sleepwake states and spontaneous behaviors in the rat. Neuroscience 76: $541-555$.

Maret S, Dorsaz S, Gurcel L, Pradervand S, Petit B, Pfister C et al (2007). Homerla is a core brain molecular correlate of sleep loss. Proc Natl Acad Sci USA 104: 20090-20095.

Miller MS, Contreras PC, Roux S, Porsolt R (2000). Modafinil improves cognitive function in rats measured by a delayed alternation task. Sleep 23(Suppl): A209.

Minzenberg MJ, Carter CS (2008). Modafinil: a review of neurochemical actions and effects on cognition. Neuropsychopharmacology 33: 1477-1502.

Mittaz L, Scott HS, Rossier C, Seeburg PH, Higuchi M, Antonarakis SE (1997). Cloning of a human RNA editing deaminase (ADARB1) of glutamate receptors that maps to chromosome 21q22.3. Genomics 41: 210-217.

Montgomery SM, Buzsaki G (2007). Gamma oscillations dynamically couple hippocampal $\mathrm{CA} 3$ and $\mathrm{CA} 1$ regions during memory task performance. Proc Natl Acad Sci USA 104: 14495-14500.

Nagappan G, Woo NH, Lu B (2008). Ama 'zinc' link between TrkB transactivation and synaptic plasticity. Neuron 57: 477-479.

Nishino S, Mignot E (2005). Wake-promoting medications: basic mechanisms and pharmacology. In: Kryger $\mathrm{MH}$, Roth $\mathrm{T}$ and Dement WC (eds). Principles and Practice of Sleep Medicine, fourth edition. Elsevier: Philadelphia. pp 418-434.

Pais I, Hormuzdi SG, Monyer H, Traub RD, Wood IC, Buhl EH et al (2003). Sharp wave-like activity in the hippocampus in vitro in mice lacking the gap junction protein connexin 36. J Neurophysiol 89: 2046-2054.

Palmer AA, Verbitsky M, Suresh R, Kamens HM, Reed CL, Li N et al (2005). Gene expression differences in mice divergently selected for methamphetamine sensitivity. Mamm Genome 16: 291-305.

Parmentier R, Anaclet C, Guhennec C, Brousseau E, Bricout D, Giboulot $\mathrm{T}$ et al (2007). The brain H3-receptor as a novel therapeutic target for vigilance and sleep-wake disorders. Biochem Pharmacol 73: 1157-1171.

Pierard C, Liscia P, Valleau M, Drouet I, Chauveau F, Huart B et al (2006). Modafinil-induced modulation of working memory and plasma corticosterone in chronically-stressed mice. Pharmacol Biochem Behav 83: 1-8.

Pierard C, Satabin P, Lagarde D, Barrere B, Guezennec CY, Menu JP et al (1995). Effects of a vigilance-enhancing drug, modafinil, on rat brain metabolism: a 2D COSY 1H-NMR study. Brain Res 693: $251-256$.

Retey JV, Adam M, Khatami R, Luhmann UF, Jung $\mathrm{HH}$, Berger $\mathrm{W}$ et al (2007). A genetic variation in the adenosine $\mathrm{A} 2 \mathrm{~A}$ receptor gene (ADORA2A) contributes to individual sensitivity to caffeine effects on sleep. Clin Pharmacol Ther 81: 692-698.

Rodriguez R, Meuth M (2006). Chk1 and p21 cooperate to prevent apoptosis during DNA replication fork stress. Mol Biol Cell 17: 402-412.

Sainsbury RS (1998). Hippocampal theta: a sensory-inhibition theory of function. Neurosci Biobehav Rev 22: 237-241.

Sanes JN, Donoghue JP (1993). Oscillations in local field potentials of the primate motor cortex during voluntary movement. Proc Natl Acad Sci USA 90: 4470-4474. 
Santi S, Cappello S, Riccio M, Bergami M, Aicardi G, Schenk U et al (2006). Hippocampal neurons recycle BDNF for activity-dependent secretion and LTP maintenance. EMBO J 25: 4372-4380.

Sharott A, Magill PJ, Harnack D, Kupsch A, Meissner W, Brown P (2005). Dopamine depletion increases the power and coherence of beta-oscillations in the cerebral cortex and subthalamic nucleus of the awake rat. Eur J Neurosci 21: 1413-1422.

Smyth GK (2004). Linear models and empirical bayes methods for assessing differential expression in microarray experiments. Stat Appl Genet Mol Biol 3: Article3.

Sokolov BP, Polesskaya OO, Uhl GR (2003). Mouse brain gene expression changes after acute and chronic amphetamine. J Neurochem 84: 244-252.

Suzuki R, Shimodaira H (2006). Pvclust: an R package for assessing the uncertainty in hierarchical clustering. Bioinformatics 22: $1540-1542$.

Tanaka J, Horiike Y, Matsuzaki M, Miyazaki T, Ellis-Davies GC, Kasai H (2008). Protein synthesis and neurotrophin-dependent structural plasticity of single dendritic spines. Science 319: 1683-1687.

Tappe A, Kuner R (2006). Regulation of motor performance and striatal function by synaptic scaffolding proteins of the Homer1 family. Proc Natl Acad Sci USA 103: 774-779.

Tiitinen H, Sinkkonen J, Reinikainen K, Alho K, Lavikainen J, Naatanen R (1993). Selective attention enhances the auditory 40-Hz transient response in humans. Nature 364: 59-60.

Timofeeva OA, Gordon CJ (2001). Changes in EEG power spectra and behavioral states in rats exposed to the acetylcholinesterase inhibitor chlorpyrifos and muscarinic agonist oxotremorine. Brain Res 893: 165-177.

Tononi G, Cirelli C (2006). Sleep function and synaptic homeostasis. Sleep Med Rev 10: 49-62.

Touret M, Sallanon-Moulin M, Jouvet M (1995). Awakening properties of modafinil without paradoxical sleep rebound: comparative study with amphetamine in the rat. Neurosci Lett 189: $43-46$.

Traub RD, Bibbig A, LeBeau FE, Cunningham MO, Whittington MA (2005). Persistent gamma oscillations in superficial layers of rat auditory neocortex: experiment and model. J Physiol 562 (Part 1): 3-8.

Traub RD, Whittington MA, Buhl EH, LeBeau FE, Bibbig A, Boyd S et al (2001). A possible role for gap junctions in generation of very fast EEG oscillations preceding the onset of, and perhaps initiating, seizures. Epilepsia 42: 153-170.

Tsai SJ, Liou YJ, Hong CJ, Yu YW, Chen TJ (2008). Glycogen synthase kinase-3beta gene is associated with antidepressant treatment response in Chinese major depressive disorder. Pharmacogenomics J 8: 384-390.
Veenstra-VanderWeele J, Qaadir A, Palmer AA, Cook Jr EH, de Wit $H$ (2006). Association between the casein kinase 1 epsilon gene region and subjective response to D-amphetamine. Neuropsychopharmacology 31: 1056-1063.

Verret L, Leger L, Fort P, Luppi PH (2005). Cholinergic and noncholinergic brainstem neurons expressing Fos after paradoxical (REM) sleep deprivation and recovery. Eur J Neurosci 21: 2488-2504.

Vertes RP, Kocsis B (1997). Brainstem-diencephalo-septohippocampal systems controlling the theta rhythm of the hippocampus. Neuroscience 81: 893-926.

Ward CP, Harsh JR, York KM, Stewart KL, McCoy JG (2004). Modafinil facilitates performance on a delayed nonmatching to position swim task in rats. Pharmacol Biochem Behav 78: 735-741.

Willuhn I, Sun W, Steiner H (2003). Topography of cocaineinduced gene regulation in the rat striatum: relationship to cortical inputs and role of behavioural context. Eur J Neurosci 17: 1053-1066.

Wisor JP, Dement WC, Aimone L, Williams M, Bozyczko-Coyne D (2006). Armodafinil, the R-enantiomer of modafinil: wakepromoting effects and pharmacokinetic profile in the rat. Pharmacol Biochem Behav 85: 492-499.

Wisor JP, Eriksson KS (2005). Dopaminergic-adrenergic interactions in the wake promoting mechanism of modafinil. Neuroscience 132: 1027-1034.

Wisor JP, Nishino S, Sora I, Uhl GH, Mignot E, Edgar DM (2001). Dopaminergic role in stimulant-induced wakefulness. J Neurosci 21: 1787-1794.

Wisor JP, O’Hara BF, Terao A, Selby CP, Kilduff TS, Sancar A et al (2002). A role for cryptochromes in sleep regulation. BMC Neurosci 3: 20.

Xie X, Dumas T, Tang L, Brennan T, Reeder T, Thomas W et al (2005). Lack of the alanine-serine-cysteine transporter 1 causes tremors, seizures, and early postnatal death in mice. Brain Res 1052: 212-221.

Yano M, Steiner H (2005a). Methylphenidate (Ritalin) induces Homer 1a and zif 268 expression in specific corticostriatal circuits. Neuroscience 132: 855-865.

Yano M, Steiner H (2005b). Topography of methylphenidate (ritalin)-induced gene regulation in the striatum: differential effects on c-fos, substance P and opioid peptides. Neuropsychopharmacology 30: 901-915.

Yano M, Steiner H (2007). Methylphenidate and cocaine: the same effects on gene regulation? Trends Pharmacol Sci 28: 588-596.

Zagnoni PG, Albano C (2002). Psychostimulants and epilepsy. Epilepsia 43(Suppl 2): 28-31.

Supplementary Information accompanies the paper on the Neuropsychopharmacology website (http://www.nature.com/npp) 